\title{
Does Exposure to Noise Lead to Decreased Regulatory Abilities, and Increased Aggression?
}

\author{
Farzaneh Pahlavan, Melana Arouss \\ Laboratory of Social Psychology: Threat \& Society EA 4471, Institut de Psychologie, Université Paris Descartes, \\ Paris, France \\ Email: farzaneh.pahlavan@parisdescartes.fr
}

Received 18 November 2015; accepted 24 January 2016; published 27 January 2016

Copyright (C) 2016 by authors and Scientific Research Publishing Inc.

This work is licensed under the Creative Commons Attribution International License (CC BY). http://creativecommons.org/licenses/by/4.0/

(c) (i) Open Access

\begin{abstract}
Recent advances in the study of affective-cognitive regulation of aggressive behavior suggest positive correlations between poor executive capacities (ECF) and negative reactivity. If the global assumption is correct what are the likely implications of predicted relation? The central issue in present research is to verify this assumption and examine how situational characteristics can alter executive performance in adults experiencing Civil War (Syrians students living in their country or in a host country) and adults experiencing peaceful life (French students) to explore some of the consequences of those modifications for aggressive and anxious tendencies. Precisely, we expect the positive correlations between poor executive performances and high dispositional as well situational aggressive and anxious tendencies, specifically for adults exposed to warfare. In order to assess executive capacities and dispositional as well as situational aggressive and anxious tendencies, during one pilot and two comparative studies [pilot study: $\mathrm{N}=\mathbf{6 0}$ female French students; first comparative study: $N=60$ French and $N=60$ Syrian students of both sexes $(50 \%)$; second comparative study: $N=60$ Syrian students of both sexes (50\%) living in France] right-handed French/Arabic-speakers participants complete twice, before and after completion executive tasks (standard neuropsychological tests) under different experimental conditions (Aversive/Neutral condition), a series of aggression and anxiety questionnaires. The results provide evidence of a dispositional relationship between poor executive functioning and negative reactivity, and extend it to situational level. For all participants, it shows that increases in impulsiveness (negative emotionality and aggressive choices) due to an aversive noise $(80 \mathrm{db})$ are concomitant with an inability to focus individuals' attention on ongoing tasks, specifically in those living directly or indirectly stressful life-event.
\end{abstract}

\section{Keywords}

Aggression, Self-Regulation, ECF, Experience of Civil War, Aversive Noise, Anxiety 


\section{Introduction}

Given their ability to adaptation, transactions between humans and environment have generally positive outcomes. However, adaptation to environmental demands happen with costs and environmental challenges can exceed individual capacities for successful adaptation. Considered as pervasive, environmental pollutants, such as odor, heat, noise... have direct et/or indirect effects on various aspects of individuals' physical and mental functions, interfering adaptation processes. Suboptimal and imbalance environmental conditions caused by environmental pollutants, specifically noise exposure, are linked to stress and seem to be associated with physical and psychological syndromes, such as chronic anxiety. On the other hand, stress research and anxiety study have well-established their direct/indirect relationship with aggressive tendencies [1] [2]. As a matter of fact, there are a variety of ways by which emotions and affective processes influence social behaviors, including aggression. Nevertheless, the effects of environmental stressors on the regulatory processes of social behaviors have not been clearly established, yet. The present research deals with the effects of environmental noise on various indices of affective-cognitive regulation, focusing specifically on anxiety and its related behavior: aggression. The main aim of the present study is to get some clearer answers about unsolved questions related to why and how social and environmental pollutants do affect psycho-sociological well-being and social behavior.

\section{Environmental Stressors}

Given their physical and psychological components, physical environmental stressors have a wide range of effects on health and behavior, specifically in function of duration of stress exposure, either acute or chronic. Individuals' ability to escape or to extinguish physical environmental stressors is limited, therefore exposure to environmental stressors is often chronic and their effects are more consequential. For example, biological study of stress has established a reliable link between chronic stressors and impaired immunological responses, while acute stressors seem to have few consequences [3]. Psychological study of stress has shown association between air pollution and odor annoyance with physical and mental health, including depression and annoyance [4] [5]. Appraisal and motivational consequences of exposure to environmental stressors, such as crowding, traffic congestion, and pollution in terms of learned helplessness have been mentioned, too. Accordingly, whenever repeated attempts to cope with such aversive environmental conditions fail learned helplessness and sometimes depressive symptomatology [6] may occur. Among the consequences of learned helplessness are decrements in learning new tasks, diminished feelings of control [7]. In several investigations, odeurs are associated with annoyance and negative evaluations of the immediate environment, depending on personal factors, such as age, gender, affective style, as well as by attitudes towards industry and authorities in general, and the air pollution source in particular [8]. Responses to the environmental stressors have been found to vary when situational factors are manipulated in order to change appraisals of those factors (e.g. when real or perceived opportunities for control). In the same vein, excessive heat has been related to increased levels of aggression and hostility in an inverted U-shaped relationship ([9] but sees [10]). In addition, the effects of chronic stress seem to be worst for people at risk for developing physical as well as psychological or behavioral problems. For instance, if one has a family history of health problems (e.g. heart disease, diabetes, high blood pressure...) or a personal history of psychological (e.g., anxiety, anger, depression...) or behavioral problems (e.g. externalizing problems such as aggression), then chronic stress may trigger these disorders.

\section{Noise as Environmental Stressor}

Like other physical environmental stressors, noise has both a significant physical component (unwanted) as well as psychological component. However, its impacts differ, in some respects, from other environmental stressors. Its physical characteristics, such as intensity (e.g. decibel), frequency (e.g. pitch), periodicity (continuous or intermittent), and duration (acute or chronic) are objectively perceived and treated by temporal lobe in the brain [11]. However, unwanted sound interfering in ongoing activities and communications ([12], p. 375), noise could be harmful for health with or without subjective perception. In addition, recurrent or persistent exposure to ambient noise seems to be more damaging. Given induced chronic stress responses, it can interfere with adaptation process [11]. The research examining the effects of sound on health has shown that intermittent, high-frequency, short-duration, intense sounds create greater disturbance and probably have larger effect on health than do continuous, low-frequency, long-duration, and low intensity sounds [13]. However, the effects of persistent noise 
have been related to feelings of annoyance and helplessness, too [14].

In addition to its physical characteristics (intensity, pressure level, frequency, periodicity, and duration), other characteristics of noise are also important in determining the interpretation of the perceived sound. These include its psychological components such as predictability of noise; episodes (random or fixed interval); attitudes to the noise source; the meaning of the noise; and the degree of personal control over it. However, it is difficult to isolate the effect of particular sound on health because its psychological and physical components play a central role in perceiving noise and most noises are a mixture of frequencies, more or less persistent [14]. The major differences for noises from other environmental stressors are that it is readily perceived and that the source is often identifiable, and associated with that, there may be particular attitudes related to the source of the noise.

Thus, given its dual component (physical and psychological), noise exposure can have wide range of effects on health and behavior. There is evidence for raised high blood pressure and hypertension in relation to noise [15]-[17], raised level of cortisol [18], and even a small contribution to the risk of myocardial infraction [19]. It has been also linked to annoyance and sleep disturbance. Moreover, there is evidence that noise have effects on children's academic performances such as reading or episodic memory [12] [20] [21].

Childhood is a time of rapid growth and learning, which could be disrupted by environmental stressors, especially by the effects of noise, to which children are specifically vulnerable. In a large study around Heathrow airport, Haines and his colleagues [22] [23] found an association between chronic aircraft exposure to noise and increased hyperactivity [22] [23], without any consequent effect related to anxiety and depression. These findings were replicated in other countries, too [24]. Children with attention-deficit hyperactivity disorder (ADHD) are generally easily distracted, with a short attention span. External stimuli, such as aircraft noise, could therefore specifically interfere with their attention. However, it does not mean that aircraft noise is causing hyperactivity, but it seems create additional problems for children already experiencing mental health difficulties, by making an existing tendency worse. Nurmi and von Wright [25] have already noticed that noise during learning impaired the subsequent recall performance of children with high neuroticism scores and with high score on state-anxiety. These results and others do seem suggest associations between noise exposure and general individuals' health vulnerability. The effects of noise exposure on psychosocial well-being seem to be facilitated by other factors such as pre-dispositional and dispositional vulnerabilities [26]. Decline in well-being may be also affected through disruptive effects of noise on sleep associated with aftereffects on mood, reaction time and cognitive performance [27] [28].

Over all this suggests that environmental noise has a wide spectrum of effects across different areas of human activity (rise to nausea, headaches, changing in mood, anxiety, irritability, [29]). High level of social conflicts at work and home (absenteeism, [30]; illness-related absenteeism, [31]) have been found to be more frequent in noisy rather than quiet industries and areas. However, the findings from these studies are difficult to interpret because working or living in noisy areas may, among others, be selectively done by individuals who are not bothered by noise [32]. Nevertheless, in spite of some criticisms considering these data as resulting from study of "noise survivors", it is important to better understand how do so called "noise survivors" regulate the effects and aftereffects of noise exposure as well as psychological and/or physical recovery process triggered by it.

\subsection{Theoretical Explanation}

Potential mechanisms of noise effects on health is generally conceptualized as fitting the stress-diathesis model, in which noise exposure increases arousal, and chronic exposure leads to chronic physiological change and subsequent health effects [33]. In his early works, Cannon [34] has already noticed that animals and humans confronting dangerous situations use "fight-or-flight" motivational strategies involving the activation of the sympathetic-adrenal medullary (SAM) system which turns back to baseline only once the emergency situation has passed (homeostasis process). Considered as the first step (alarm stage) of three-step pattern of "General Adaptation Syndrome (GAS)", according to Selye [35] "fight-or-flight” responses to stress preceded a resistance stage (physical adaptive coping) and then an eventual exhaustion stage during which physical depletion of regulatory resources may occur. The study of emotion regulation on a biological level using magnetic resonance imaging (MRI) strongly suggests existence of a neural basis supporting these classic results [36]. Sufficient evidence has correlated emotion regulation to particular patterns of prefrontal activation, including the orbital prefrontal cortex, the ventromedial prefrontal cortex, and the dorsolateral prefrontal cortex. In addition, the amygdala and the anterior cingulate cortex have been found to functionally contribute to emotion regulation. Each of these structures is involved in various facets of emotion regulation and irregularities in one or more regions 
and/or interconnections among them are associated with failures of emotion regulation. An implication to these findings is that individual differences in prefrontal activation predict the ability to regulate various aspects of emotion [37].

Regarding mechanisms underlying the effects of noise on social psychological functions, there is no universally agreement but a solid hypothesis about its effects on psychological and cognitive processes underlying social performance [38] [39]. The best known models supporting this hypothesis are the transactional model developed by Lazarus and colleagues [40] [41], and its extended versions (e.g. [42]). Emphasized the continuous, reciprocal nature of the interaction between the person and the environment, according to transactional model, stress is a particular relationship between the person and the environment that is appraised by the person as exceeding his/her resources and threatening his/her well-being ([43], p. 19). However, appraisal of environmental demands and personal resources can change over time and through a particular sequence of events, starting with perception of a real or imagined emotionally relevant situation, directed attention process towards the emotional situation, its evaluation and interpretation in order to determine a relevant behavior strategy, which can be focused either on problem solving, or on emotional soothing. Stress experiences and coping results bring along immediate effects, such as affects or physiological changes, and long-term results concerning social and psychological functioning [41] [44]-[46]. Activated emotional and behavior responses, in turn, can change perception, evaluation, and interpretation of the situation. Stress related processes are therefore recursive, ongoing, and dynamics [47] which can be subjected to regulation strategies focused on antecedent of emotional response or focused on generated emotional response [48]. Antecedent-focused strategies lead to avoid or approach a situation, or modify it externally, direct attention toward or away from a situation (Distraction; [49]; Rumination; Worry; [50]; Thought suppression; [51]) or internally (Cognitive change, Reappraisal, [48]; Distancing, [52]; Humor, [53]. Response-focused strategy involves attempts to directly influence response systems (Experiential, behavioral, and physiological; [48]; Expression suppression, [54]; Drug use, [55]; Exercise, [47]).

Emotions as well as cognitions related to stress situation are therefore subject to continuous changes and their meaning depend on their underlying context. As such, regulation of stress functionally refers also to processes leading to focus one's attention to an ongoing task, using the ability to suppress inappropriate behavior in a socially tolerable manner. As an active process, stress should be analyzed and investigated through personal and environmental variables in terms of short-as well as long-term effects. Stress regulation is therefore a highly significant function in human life. In everyday life, people are continually exposed to a wide variety of potentially stressful situations. Inappropriate or extreme reactions to such situations could inhibit functional fit within society, through difficulties in controlling one's affective expression, as well as, in organization and quality of his/her thoughts and social behaviors.

\subsection{Executive Regulatory Processes and Functions}

Regulatory mechanisms refer to many processes by which the human psyche exercises control over its functions, states, and inner processes [56]. Defined as capacities of individuals to symbolically plan, represent, and control their thoughts and behaviors, regulation and self-regulation is emphasized to be fundamental to intrapersonal and interpersonal behavioral adjustment [57]. Developed during interaction between the child and his/her social environment (e.g. parents, peer), as a part of socialization process, all normal people are supposed to have regulatory capacities, including a strong subjective feeling of intention or voluntary control of their behavior [58]. Therefore, much of so called self-regulation in everyday terms involves conscious, effortful, and motivated activities by which individuals try to bring their thoughts and behaviors into accord with consciously desired standards (e.g. [59]). It is also clear that many of the dynamic processes involved (e.g. spontaneous switching between multiple goals) are automatic and unconscious (e.g. [60]). Thus, regulation and self-regulation should be defined as any conscious as well as unconscious processes involved in regulation and control of any human inner states or responses, including thoughts, emotions, impulses, performance, as well as attention [56].

In her works focused on Temperament viewed as "constitutionally based individual differences in reactivity and self-regulation, in the domains of affect, activity, and attention” ([61], p. 100), Rothbart [62] distinguishes two major components of temperament, one associated with reactivity and the other related to voluntary self-regulation. In this view, reactivity refers to "responsiveness of emotional, activation, and arousal systems" whereas self-regulation is viewed as "approach, avoidance, and attention that modulate reactivity" in function of 
social demands of situation [63]. Eisenberg's model of emotion-regulation [64]-[66] differentiates also between reactive control and executive control. However, in her perspective, only the executive control is truly part of emotion regulation. Accordingly, in contrast to executive controls, reactive controls are so automatic that they often are not under voluntary control [64].

Working on attentional regulatory processes, Posner and colleagues try to bring a flexible and dynamic view of the self-regulation mechanisms and propose to distinguish three attention networks in the brain serving different functions and having different neural anatomies (e.g. [67]-[69]). These networks are emphasized to be the sources of attention and to operate in conjunction with other neuronal structures to regulate basic cognitive and emotional processes, with which people cope in their everyday existence [66] [56]. The first network controls Altering and provides achievement and maintenance of a state of high sensitivity to incoming stimuli involving frontal and parietal region of right hemisphere. The second network Orienting allows selection of sensory information and involves superior parietal cortex, temporal parietal junction, frontal eye fields, and superior colliculus. The third, the Executive Attention network functions to monitor and resolve conflict involving the anterior cingulated, lateral prefrontal cortex, and basal ganglia [69]. There is evidence that the prefrontal cortex, particularly on the right side, is involved in control through inhibition of the competing systems (e.g. [70]). The executive attention network provides, therefore, executive functions [71] in order to facilitate or inhibit the functions of other networks and to underlie self-regulation mechanisms (e.g. inhibition of an impulsive reaction to irrelevant stimuli while pursuing a cognitively represented goal; [72]-[74]. For example, one of the main neural structures of the executive attention network (the anterior cingulated gyrus), is linked to specific functions related to self-regulation [75] [76] including the control of working memory, response to error, monitoring of conflict, and also regulation of emotion. In emotion studies, this neural structure is often seen as part of a neural network (the orbital frontal cortex and amygdale) that regulates emotional responses to sensory information. Activation of this neural structure is observed whenever people are asked to control their automatic reactions to strong positive [77] or negative [78] emotions.

Thus, conceptually, it is conceivable to expect both reactive and cognitive controls to be involved in individuals' behavioral regulation because behavioral problems (e.g. externalizing problems such as aggression) are often defined partly in terms of problems in controlling emotion (e.g. displaying high level of anger or anxiety). Nevertheless, some forms of behavioral problems, involving disorders of affect, may be best conceptualized as disorders of the context regulation of affect [75]. That is, the emotion characterizing these disorders would be normative and appropriate in certain contexts. For example, anxiety disorders typically involve the expression of normal emotion in inappropriate or non-normative contexts. Therefore, appropriately contextual regulation of emotional behavior might involve both reactive and cognitive controls.

Indeed, the role of context in terms of executive functions and affective regulation is relatively understudied. For Davidson, Fox, and Kalin [75] the contextual regulation of emotion is assumed to proceed relatively automatically. Thus, regulation of emotion may sometimes demand precedence over other aspects of self-regulation. However, emotions do not uniformly affect individuals' self-regulatory capacities. While some emotions (both positive and negative) can cause individuals to ignore relevant information, other emotions may mobilize their attentional capacities. Failure to allocate attention and to regulate cognitive processes in order to incorporate all the relevant information, may contribute to self-defeating behavior as well as to unrealistic vision of the social world [79]. In the same line, the acute bad feelings may stimulate the desire to make them stop to a degree that can cause self-regulation failure in the long run [80]. In all cases the individuals apprehend context based on their analysis of current context, and they try to adjust their behavior in an apparently appropriate way regarding current context. Thus, study the role of context in affective and cognitive processes could lead to discover different causal pathways leading to the self-regulation success or failure.

\subsection{Age and Gender Related Differences in Executive and Reactive Regulations}

In Rothbart's approach, self-regulation is considered as a major part of developmental organization of temperament and personality, which follows a course of development and coincides with increased ability to regulate internal states and reactions to external events. Some of these self-regulatory mechanisms accompany the maturation of attentional mechanisms [74]. In fact, emotional-regulation, specifically stress-regulation efforts during childhood manifesting as an approach towards pleasant and an avoidance of unpleasant stimuli, seems to be guided primarily by physiological response systems [81]. Nevertheless, rapid development of executive functions, during the first and second years of life, allows development of volitional skills, which by practice become 
less controlled and more automatic [69]. A three-month baby is able to engage in self-soothing behaviors like sucking and reflexively to react to feelings of distress [82]. Between three and six months, basic motor and attentional mechanisms allow child more effective affective approach/avoidance regulation in relevant situations [83]. Engaging in self-distraction and help-seeking behaviors, at one year, children are able to explore their surroundings more actively and with greater flexibility appreciating their caregivers' abilities to provide them support and attention [84]-[86]. The caregivers' emotion regulation strategies to attenuate distress or to comfort children impact deeply their emotional and behavioral development and regulation [87] [88]. Two-year children are capable of actively regulate their emotions and employ regulation strategies and tactics to influence various emotional states [89] [82]. In addition, given maturation of brain functioning, their linguistic and motor skills permit them to manage and control more effectively their emotional and behavioral reactions [69]. Between six and 10 years, children begin to apprehend the contexts in which expression of certain emotions are socially appropriate and therefore there is a trend towards the use of more cognitive emotion regulation strategies instead of more basic ones [90]. During these years, children who are frequently exposed to negative emotion at home will be more likely to have difficulties in regulation of negative emotion [91] [94]. At adolescence, regulatory capacities and spontaneous use of cognitive emotion-regulation strategies increase. In addition, taking into account the social context and the significance of interpersonal outcomes (e.g. sympathy expectation), decision making become more complex in adolescence [95] [96].

Emotional regulation focuses therefore on providing the appropriate emotion in the appropriate circumstances. This skill, although apparent throughout all cultures [97], has been shown to vary in successful application at different age groups. It seems with time people develop a better ability to regulate their emotions. This ability in adults allows individuals to react in a more appropriate manner in some social situations, and therefore to avoid adverse situations that could be detrimental [98]. Failure in emotional regulation is associated with psychosocial and emotional dysfunctions [99] caused by traumatic experiences due to an inability to regulate emotions. At an early age, these traumatic experiences could be sometimes associated with bullying. Children who can't properly self-regulate express their emotions in a variety of ways, including screaming, lashing out with their fists, or bullying other children. Behavior problems are, in general, characterized by negative reactivity [100]. High negative reactivity could diminish capacity to attend social cues, leading to misinterpretation and incorrect processing of social information (e.g. Hostile attribution bias; [101]), with the risk for psychopathology such as externalizing disorders [102]. Indeed, externalizing/internalizing behavioral problems are based on individuals' reactions to stressors. Externalizing behaviors are primarily characterized by actions such as antisocial behavior, hostility, and aggression which may, in some cases, coincide with the inhibitory problems of attention-deficit/hyperactive disorder (ADHD; [103] [104]).

There is therefore evidence suggesting age as moderator of relation between behavioural problems and the development of executive control. However, there is debate about the moderator role of gender (but see [105]). In terms of general cognitive abilities, despite differences noted on specific ability tests, males and females seem do about the same. In addition, analyses of trends over time suggest that gender differences in scores on cognitive ability tests decrease over the years [106]. There is only some agreement in regard to the eventual effects of the differences in information processing (such as attention and perception). In fact, researchers have consistently found that males show an advantage in visual-spatial abilities [107]-[112], and females show an advantage for verbal abilities [107] [108] [113] [114]. Thus, many researchers emphasize that there are more similarities than differences between the cognitive and affective abilities of males and females (see [115]). There is also much variability within gender groups, particularly for males [108], males are over-represented, with higher percentages identified as having disabilities, including dyslexia, delayed speech, and attention deficit/hyperactivity disorder, as well as giftedness. However, there is also evidence that methodological bias plays a role in undercounting females with dyslexia [116], as well as females who are gifted. For Stenberg [115], gender differences refer only to average and they may originate from a number of factors, many of which change over time.

Behaviourally, because of the higher prevalence of serious externalizing problems among males than females, most of the extant literature in this area has been conducted with male sample. Thus, it is not clear whether links between poor emotion regulation (anger burst) and externalizing behaviour (particularly reactive aggression) apply similarly to females. In females, research has documented significantly lower rates of overt aggression, but higher rates of relational aggression (for example, indirectly retaliating against a peer by gossip), suggesting, among others, a methodological bias of traditional studies of aggression [117]. 
For both sexes, executive changes over time are therefore highly sensitive to environmental influences and socialization, suggesting a fundamental continuity in development, with social and emotional development at childhood laying the groundwork for adult functioning (see [61] [105] [118] [119]). There is also growing evidence of typically association between externalizing problems and negative emotionality such as anger, frustration, and anxiety [61] [64] [120] [123]. Such feelings may motivate externalizing behaviors, and externalizing children, especially if aggressive, may become more angry and anxious over time because they tend to be rejected and victimized by peers [124]. However, the question regarding stability or variability of these relations at older ages is not established, yet.

\section{Present Research}

As an obvious feature of normal socialization, and in sense of resisting temptation (voluntarily control of current impulses for the sake of expected future benefits), self-regulation capacities could be therefore of specific interest to understand social behaviors such as aggression and its contextual adjustment. Indeed, there is growing evidence that individual differences in cognitive functioning is a risk factor for aggressive behavior at dispositional level, that is some people's behavior may be chronically influenced by impulsive processes across time and situations (e.g. [64] [125] [130]). However, one of the important challenges to better understanding selfregulation of aggressive behavior is to determine implication and role of different contexts in activating affective and cognitive processes leading to such behavioral choices. Only few studies have directly focused on situational differences in aggression related to higher order regulatory processes in terms of executive functions (e.g. [131] [133]). If aggressive tendencies depend on chronic or contextual alteration of executive functions, the improvement of executive controls by training programs should be of utmost importance for patients with psychopathology such externalizing disorders or with brain injury associated with Dysexecutive Syndrome (DES) as well as for professional such as health care workers with the risk of burnout.

As a matter of fact, the existing literature in these area shows that in spite of the early-development of the executive attention network (between ages 2 and 7), with practice, the ability to self-regulate can be contextually improved and trained. Actually, the results of our own research [132] analyzing effects of situational characteristics (experimental feedbacks: success, neutral, failure) on executive performance and affective reactivity in persons with Dysexecutive Syndrome (DES) and healthy adults (students, health workers) showed for all participants that increases in impulsiveness (negative emotionality and aggressive choices) due to a negative feedback were concomitant with an inability to focus individuals' attention on ongoing tasks. In addition, recent training programs have resulted in improved executive control and behavioral adjustment within special population (patient with specific brain injury; [134]; ADHD, [69] [135] [136]) and domains (attention process, working memory), even in animal [137].

\subsection{Overview}

The present research was designed to test the link between executive functions, and chronic/contextual aggressive tendencies using an aversive stimulation (noise of $80 \mathrm{~dB}$ ), in adult populations from France and Syria. The central issue was to examine whether contextual characteristics could alter executive controls, and to explore the behavioral consequences of these executive alterations in adults exposed to stressful life-event. We focused on a variety of executive functions thought to be relevant to control of attention, resistance to interference, error detection/correction, and response inhibition. Given the lack of critical pieces of information regarding the situational differences in aggression related to higher order regulatory processes, one pilot and two two-part comparative studies were conducted. The first part basically dealt with relatively stable individual differences linked to aggressive tendencies. The second part of the study would look at externally activated processes, primed by aversive stimulation (presence vs. absence of a noise of $80 \mathrm{~dB}$ ) that might contribute to depletion of executive capacities as well as augmentation of aggressive tendencies.

The first comparative study was designed to assess in a student sample, a) whether there was a positive relation of deficits in executive controls and aggressive tendencies after receiving an aversive stimulation; $b$ ) if this relation was found in absence of the aversive stimulation; c) in French as well as Syrian participants. The second comparative study was a replication of the first one and examined the same issues in two Syrian samples: a sample of students arrived in France before (indirectly exposition to the Syrian Civil War) and a sample arrived after outbreak of the Syrian Civil War by July 2011 (directly exposition to the Syrian Civil War). The specific 
objective of the second study was focused on comparison of the data from individuals directly exposed (arrived in France after beginning of the Civil War) to those indirectly exposed (arrived in France before beginning of the Civil War) to warfare in function of aversive noise (presence vs absence of a noise of $80 \mathrm{db}$ ) as an aspect of living extreme adverse situations.

The case of Syrians living in France is of particular importance for our research because of their direct vs. indirect ongoing experience of extreme stressful situation that might be associated with extreme depletion of executive capacities as well as highest aggressive tendencies given their used strategies to cope with extreme conflict situations. According to studies published to date, many of the anxiety symptoms can be seen as a direct result of exposition to stressful situations. We believe that comparative studies of the relation between affective and cognitive behavioral regulations in such cases might provide new perspectives on intervention programs in social health sectors.

\subsection{Hypotheses}

Based on our prior findings [132] and the notion that negative emotionality involves executive control (e.g. [64] [100]), we hypothesized that executive deficits would be positively correlated with aggressive tendencies (Correlative Hypothesis), and these relations would be observed for all participants. That is, some individuals' behavior may be chronically influenced more by impulsive processes independent of any experimental manipulations. However, because executive control may be dynamically modulated by characteristics of current context, the effect of its deficits on aggressive tendencies was predicted to become stronger for participants in aversive condition (Causal Hypothesis). Finally, our last hypothesis was gender related individuals' differences. Given controversial issue regarding gender as moderator of executive functions, our gender-related hypotheses was based only on gender-differences regarding relations of experimental conditions and aggressive tendencies. More precisely, (Gender-related Hypothesis) we expected more aggressive behavioral intention in men and higher emotional negativity in women, particularly in aversive condition.

However, as specific hypothesis, for Syrian participants (exposed to civil warfare and experiencing extreme stressful life-event) we hypothesized that causal effect of experimental aversive stimulation would be, chronically and contextually, highest particularly in the case of those experiencing warfare directly (psychological warfare).

\subsection{Method}

\subsubsection{Ethical Issues}

We give careful consideration to the ethical issues surrounding the use of our experimental procedure in terms of aversive stimulation (presence/absence of aversive noise). Given lack of a formal research Ethics Committee for non-clinical research project involving human participants, we recruited only participants who agreed a consent form in accordance with the ethical principles of the American Psychological Association. In addition, we included participants who reported no recent traumatic events, informing them by consent form that they were free to withdraw at any time.

\subsubsection{Pilot Study}

\section{Participants}

From February to March 2012, sixty female students of psychology aged between 18 and 25 years $(M=19.55$ years, $S D=1.52$ ) from University Paris-Descartes were recruited, through a convenience sampling technique. They were recruited via announcement put up around Faculty. Participants were all French speakers, and none reported any neuropsychological or developmental disorder. They participated on a voluntary basis, and after having read and signed a double informed consent form before starting and after finishing the experimental sessions. Participants were randomly assigned to one level of the experimental condition (presence/absence of aversive stimulation).

\section{Experimental Conditions}

There were two experimental conditions (presence, and absence of aversive stimulation). During completion of French-version of a battery of tests currently used to evaluate executive capacities, a half of the participants were exposed, through a headphone, to a continuous noise of $80 \mathrm{~dB}$ in intensity, while the other half accomplished executive tasks without any disturbing noise. Induction of experimental stimulation was verified using a 
check experimental procedure. Participants were asked to indicate on a 4-point intensity scales ranging from 0 (not at all) to 4 (extremely) the extent to which they were disturbed by noise during completion the experimental tasks.

\subsubsection{Material and Measurement}

\section{Assessment of Executive Function}

In order to evaluate executive capacities we applied a digitalized version of a battery of worldwide standardized neuropsychological tests currently used by French specialists in the field. The choice was based on the nature of the investigated executive functions. We chose the executive capacities of inhibition, initiation, planning, and selective attention or mental flexibility, which are currently used to assess inhibitory control [138]. For having a pure measure of selective attention and inhibition control, we used a task of reaction time (Go-No/go) and Modified Card Sorting Test (WCST; 139). In addition, for measuring planning and selective attention (mental flexibility) we used respectively Tower of Hanoi, and Trail Making Test Part A-B.

\section{Measurement of Inhibitory Control}

For assessment of inhibition controls we used two tests: Modified Card Sorting Test (WCST; [139] and Go/No-go tasks.

The Wisconsin Card Sorting Test (WCST) is a neuropsychological test of categorization, measuring the ability to display flexibility whenever rules of categorization changes. Initially, a number of stimulus cards are presented to the participant. For digital version, 4 stimulus cards were presented on the screen all the time. For each trial one to-be-matched card was presented and participant had to touch one of the 4-stimulus cards as being matched (because of the shape, color, or number of shape on the to-be-matched card) with the trial card. In the case of the non-clinical population or a sample of persons with slight or moderate Dysexecutive Syndrome (DES) the flexibility measure is not useful, because the number of accomplished categories is always maximal. Therefore, we analyzed only inhibitory capacity or perseveration errors measured during this task (preservation errors; [140] [141]).

Go/no-go test refers to a pass/fail test (or check) principle. In psychology Go/No-go tests are used to measure a participant's capacity for sustained attention and response control. In the case of our studies, during Go test participants were required to press a button each time a centered black circle of $2 \mathrm{~cm}$ diameter was presented on the screen (given stimuli: press a button-Go) for a number of trials. During No-go, the participants were asked to inhibit that action under the same condition (not press that same button when the black circle was presentedNo-Go). Scoring was based on the time spent to accomplish trials under each condition. Go condition score was considered as a measure of selective attention, and No-go condition score as inhibitory capacity.

\section{Measurement of Mental Flexibility and Selective Attention}

The Trail Making test (part A and B) is a test of speed, and the examiner takes into account both the time taken and efficiency to carry out the test. Part A consists of encircled numbers from 1 to 25 randomly spread across a sheet of paper. Respondents are required, to connect the numbers in order, beginning with 1 and ending with 25, as fast as possible. Part $\mathrm{B}$ requires the respondents to connect numbers and letters in an alternating pattern (1-A-2-B-3-C, etc.) as fast as possible. Participants were required to draw, as fast as possible, links between numbers and letters on a page in an alternating sequence. In general, scores are calculated by adding the time taken by the respondents to complete both Parts.

\section{Measurement of Planning}

The Tower of Hanoi task involves reaching a goal state through the execution of a series of moves. The objective is to move a pyramid of variously sized disks from one peg (start peg) to another (goal peg). Only one disk could be transferred per move and it had to be smaller than the disk underneath. Participants are required to accomplish the task with the minimum of moves (three-disk: 7 moves; four-disk: 15 moves). Each participant was shown the materials and told the rules. The experimenter then demonstrated how the problem could be resolved with 3 disks. The participants were told that they had to solve the same problem with 4 discs.

Performance indices for all used tests were the times spent by participants to complete each test, except for The Wisconsin Card Sorting Test. The order of tests and tasks was as follow: each session started with The Wisconsin Card Sorting Test and Go/No-go tasks followed by Tower of Hanoi tasks and The Trail Making test part A-B. The presentation of a digitized version of the tests, collection of responses, and latency of the responses were controlled and recorded by an IBM compatible computer, except for The Trail Making test which was presented in its original version (paper/pencil version). 


\section{Assessment of Dispositional and Situational Aggressive Tendencies}

To measure aggressive tendencies before experimental stimulation (dispositional measure) and after (situational measure) we used the self-reporting method developed by O'Connor, Archer, \& Wu ([142] APQ). The Aggressive Provocation Questionnaire or APQ is a widely used measure. In the present study we used the French version of APQ. The French version of APQ is available in two formats: a short (12 vignettes; validated by [143]) and a long (24 vignettes; [144]) versions. Following the APQ's general instructions, the participants were asked to imagine being in a series of situations and to indicate (a) how s/he would feel in each situation (angry, frustrated, or irritated), measured on a 5-point intensity scale ranging from 0 (not at all) to 4 (extremely), and [2] how s/he would react to each situation by choosing one of five randomly-ordered action responses (avoidance, denial, distant anger, assertive behavior, or aggressive behavior). Following the O'Connor et al. procedure, the participants' behavioral scores were calculated adding up the number of situations checked for each behavioral choice (only one choice out of 5 per situation) and dividing this sum by the total number of items (12 scenarios for each experimental session). Emotional scores were equal to the sum of the intensity value on each emotional dimension. Given our hypotheses and objectives, in the case of the present study we calculated and analyzed anger and aggression scores.

\section{Assessment of Trait and State of Anxiety}

In the present study, we used the French version of the State-Trait Anxiety Inventory (STAI, [145]) in order to measure participants' level of anxiety at dispositional (Trait) as well as situational (State) levels. The StateTrait Anxiety Inventory is a two-part self-report questionnaire. The standardized version of the Trait-Anxiety Scale contains 20 items. For each item, the respondent was asked to indicate on a 4-point scale from "never" to "always" how frequently s/he would feel in that way, in general. The standardized version of the State-Anxiety Scale contains 20 items, too. For each item, the respondent was asked to indicate on a 4-point scale from "not at all” to "very much so" how s/he feels in that way, right now, at this moment.

For this two-part questionnaire a low score on each scale corresponds to a low level of felt anxiety as a personality trait or state.

\subsubsection{Procedure}

After having been introduced to the experimental box, the participants were invited to sit in a chair facing a uniformly gray computer screen. The experimenter adjusted a headphone to the participant's head. All experimental instructions were transmitted via the headphone to the participant. After having been informed of the apparent goal of the experiment, participants read and signed the first part of an informed consent form. Then, during a first session (20 - 30 minutes), they completed a questionnaire measuring aggressive tendencies (12-items APQ). In the second experimental session (30 - 45 minutes) participants performed the executive tests and filling out the questionnaire measuring aggressive (12-items APQ) and anxiety (STAI) tendencies. At the end of the second experimental session, participants were asked to indicate on a 4-point intensity scales ranging from 0 (not at all) to 4 (extremely) the extent to which they were disturbed by noise during completion of experimental tasks. Then after, they probed for suspicion and skepticism, but none reported knowledge of the study's purpose. Finally, they signed the second part of an informed consent form before being thoroughly debriefed and thanked.

\subsection{Statistical Analysis}

We checked the distribution of the data and tested for variance heterogeneity. The data were normally distributed and analyses did not provide evidence that the assumption of homogeneity of variance had been violated.

\subsubsection{Results}

\section{Experimental Stimulation Check}

Before testing our research hypotheses, participants' scores on disturbing effects of noise were analyzed in order to verify the effect of experimental condition. ANOVA with one factor was used. Analysis of ratings revealed significant effect of experimental condition, $F(1,58)=6.36, p<0.02, \eta^{2}=0.10$, with the highest disturbance score for participants in aversive condition ( $M=3.17 \mathrm{vs} M=2.43$ ).

Relationship between Impaired Executive Performances and Aggressive Tendencies

As shown in Table 1, measures of negative reactivity (APQ-aggressive, and STAI-anxiety tendencies) and 
impaired executive performance were generally positive but not significantly correlated, except between anger with perseveration, on the one hand ( $r=0.25, p<0.05)$, and on the other hand with planning $(r=0.25, p<0.05)$. In the same vein, correlation between Trait-Anxiety and executive inefficiency in terms of mental flexibility was significantly positive $(r=0.25, p<0.05)$. In contrast, the level of anxiety tendencies (Trait-Anxiety; state-anxiety) were negatively correlated with impaired executive performance in terms of planning (respectively $r=-0.21, p>0.05, r=-0.26, p<0.05$ ). Thus, for all participants, impaired executive performance in terms of inhibition and planning was higher in angry individuals. In the same vein, more anxious individuals seemed to have more difficulty to follow new rules and instructions. However, to plan a goal-directed-action, more anxious individuals (Trait as well as State anxiety) seemed to be more resourceful than less anxious ones.

Therefore our results are partially consistent with those reported in the studies published to date. In sum, consistent with our hypothesis 1, impaired executive scores (executive inefficiency on inhibition, planning) were observed for more angry individuals. For more anxious impaired executive concerned rather mental flexibility.

\section{Effects of Experimental Stimulation on Negative Reactivity and Executive Performances}

Given small sample size, study's design, and also as an exploratory step of our research, we analyzed the data using a Multivariate factorial plan with one factor (Experimental condition). Multivariate analysis of the scores on APQ scales, STAI, and those on executive performances showed a significant effect involving experimental condition, $F(1,48)=5.81, p<0.0001, \eta^{2}=0.57$.

Univariate analyses of these effects revealed only two significant main effects related to experimental stimulation for planning (Hanoi) capacity and intensity of anger (APQ). As shown in Table 2, compared to neutral condition, participants in aversive condition seemed to have more difficulties to plan goal-directed actions. In addition, they expressed more felt anger facing conflict situations of APQ. No other significant effect related to experimental design was found.

\subsubsection{Discussion}

Consistent with studies published to date and our past study [132], our pilot study confirmed partially relationship

Table 1. Observed inter-correlations for negative reactivity, and executive functions scores.

\begin{tabular}{|c|c|c|c|c|c|c|c|c|c|c|}
\hline & 1 & 2 & 3 & 4 & 5 & 6 & 7 & 8 & 9 & 10 \\
\hline 1. Perseveration (WCST) & 1.00 & & & & & & & & & \\
\hline 2. Attention (Go) & 0.08 & 1.00 & & & & & & & & \\
\hline 3. Inhibition (No-Go) & 0.03 & 0.04 & 1.00 & & & & & & & \\
\hline 4. Planning (Hanoi) & 0.39 & -0.02 & 0.16 & 1.00 & & & & & & \\
\hline 5. Attention (TMTA) & 0.03 & -0.14 & 0.07 & -0.10 & 1.00 & & & & & \\
\hline 6. Mental Flexibility (TMTB) & -0.03 & -0.04 & 0.04 & -0.07 & 0.06 & $1.00^{2}$ & & & & \\
\hline 7. Anger (APQ) & 0.25 & 0.00 & -0.07 & 0.25 & -0.01 & 0.10 & 1.00 & & & \\
\hline 8. Aggression (APQ) & 0.06 & -0.03 & -0.04 & 0.06 & -0.12 & 0.10 & 0.20 & 1.00 & & \\
\hline 9. Anxiety State (STAI) & -0.10 & -0.02 & -0.14 & -0.22 & 0.07 & 0.08 & -0.06 & -0.21 & 1.00 & \\
\hline 10. Anxiety Trait (STAI) & -0.07 & 0.04 & -0.07 & -0.26 & 0.12 & 0.25 & 0.04 & -0.21 & 0.70 & 1.00 \\
\hline
\end{tabular}

Note: $r>0.24$ are significant at $p<0.05$.

Table 2. Les différences entre les deux groupes expérimentaux selon la condition expérimentale experimental groups/ measures.

\begin{tabular}{cccccccccc}
\hline Bruit & $\begin{array}{c}\text { Perseverance } \\
\text { (WSCT) }\end{array}$ & $\begin{array}{c}\text { Attention } \\
\text { (GO) }\end{array}$ & $\begin{array}{c}\text { Inhibition } \\
\text { (NO-GO) }\end{array}$ & $\begin{array}{c}\text { Planning } \\
\text { (Hanoi) }\end{array}$ & $\begin{array}{c}\text { Flexibility } \\
\text { (TMTB) }\end{array}$ & $\begin{array}{c}\text { Anger } \\
\text { (APQ) }\end{array}$ & $\begin{array}{c}\text { Aggression } \\
\text { (APQ) }\end{array}$ & $\begin{array}{c}\text { Anxiety } \\
\text { State }\end{array}$ & $\begin{array}{c}\text { Anxiety } \\
\text { Trait }\end{array}$ \\
\hline Sans & $99,087 \mathrm{~ms}$ & $102,708 \mathrm{~ms}$ & $112,143 \mathrm{~ms}$ & $55,753 \mathrm{~ms}$ & $108,472 \mathrm{~ms}$ & 28.33 & 0.136 & 41.17 & 47.07 \\
Avec & $114,778 \mathrm{~ms}$ & $97,402 \mathrm{~ms}$ & $112,729 \mathrm{~ms}$ & $75,881 \mathrm{~ms}$ & $99,760 \mathrm{~ms}$ & 32.70 & 0.131 & 40.23 & 44.47 \\
\hline
\end{tabular}

Note: Measurement unites for executive performances are expressed in Millisecond. *: Significant effect $=$ or $<0.05$. 
between poor executive functioning and negative reactivity in an experimental condition. It showed that an aversive noise interfered significantly with participants' performance in terms of planning and fostered anger feelings. This fact may in part explain why individuals who grow in adverse environmental might develop poor executive capacities, and be emotionally vulnerable and more akin to anger and antisocial behavior. As mentioned by Kochanska [146], development of executive controls and self-regulations is a crucial step of socialization. However, in spite of an early-development of these capacities, our data showed that situational characteristics could alter individuals' reactivity and control capacities in adulthood. Adults are supposed to be able to regulate their affective experiences and shift their attention away from the negative cues related to anger or other impacts of immediate self-threatening environment. Nevertheless, our data showed that regardless of age or developmental step of individual, self-threatening context could cause a deficit in social information processing, which could contribute to a high emotional reactivity.

However, the results of our pilot study established that relations between executive controls and affective reactivity were not due solely to the individual dispositional in a sample of female students, as the most convenient population. Yet, given the nature of our research and our objectives, further studies with other populations would be of great important. In this vein, we realized two comparative studies in order to extend our finding to populations exposed to extreme stressful situations, Syrian student samples living in their country or in France.

\subsection{Comparative Studies}

The results of the pilot study has supported our preparatory work and provided convincing evidence that the work has been thoroughly thought through. However, few methodological problems subsisted regarding adaptation of the experimental material and procedure for our comparative studies. Therefore, for our comparative studies we developed a Syrian version of used tests and self-reporting questionnaires. Otherwise, the procedure represented a replication of the pilot study, and used the same paradigm (aversive stimulation vs. neutral condition), material, and procedure. In addition, given critical condition in Syria and difficulties to accessing the Syrian students living in Paris, we applied a convenience sampling technique in order to recruit our participants, without any calculation for sample size.

Principal objective of our comparative studies was to reassess and extend the results of the pilot study. Therefore, its' primary aim was to examine the relation between executive performance and affective reactivity (aggressive and anxiety tendencies) using an aversive experimental stimulation through two studies: French-Syrian and Syrian-Syrian comparative studies. Therefore, for first comparative study, our samples were composed by French and Syrian students living in their respective countries. The French part of study was conducted in September/December 2014. The Syrian part took place in December 2014/January 2015. For the second comparative study, our samples were composed by Syrian students arriving in France, as host country, before or after beginning of Syrian Civil War (about July 2011), and it took place in February/April 2015. Based on prior findings and the results of our pilot study, for all participants we predicated the same correlative relation between executive deficits and negative reactivity measured before and after inducing experimental stimulation (Correlative Hypothesis), and causal effect of aversive stimulation on those relations (Causal Hypothesis). We also examined our gender-related hypothesis related to aggressive tendencies. As specific hypothesis, for Syrian participants (exposed to civil warfare and experiencing extreme stressful life-event) we hypothesized that causal effect of experimental aversive stimulation would be, chronically and contextually, highest particularly in the case of those experiencing warfare directly (psychological warfare).

\subsubsection{Method}

For our comparative studies we used the French/Arabic (respectively for French and Syrian participants) digitalized versions of executive tasks, self-reporting questionnaires, and check experimental procedure. Otherwise, the procedure represented a replication of the first study, and used the same material.

\subsubsection{Participants}

\section{French-Syrian Comparative Study}

Participants: Sixty French students (female $=30$, male $=30)$ aged between 18 and 38 years $(M=21.85$ years, $S D=3.79)$ of the Montpellier University in France, from September to December 2014, and 60 Syrian students (female $=30$, male $=30$ ) aged between 18 and 35 years $(M=22.10$ years, $S D=3.63)$, of the Tartous University in Syria, from December 2014 to January 2015, participated in this study. They were recruited via announce- 
ment put up around faculty. Participants were all right-handed native French/Arabic speakers, and none reported any neuropsychological or developmental disorder.

All subjects from both countries participated on a voluntary basis, and after having read and signed the same double informed consent form used for our pilot study before starting and after finishing the experimental sessions. Participants were randomly assigned only to one level of the experimental condition.

\section{Syrian-Syrian Comparative Study}

Participants: Sixty Syrian students (female $=30$, male $=30$ ) aged between 18 and 35 years $(M=23.41$ years, $S D=4.05)$ from different Parisian Universities in France took part in this study, conducted from February to April 2015. They were recruited via internet or phone call by one of the authors given her origin (Melana Arouss). They were all right-handed native Arabic speakers, and none reported any neuropsychological or developmental disorder. All subjects participated on a voluntary basis, and after having read and signed the same double informed consent form used for our pilot study before starting and after finishing the experimental sessions. Participants were randomly assigned only to one level of the experimental condition.

\subsubsection{Development and Validation of Arabic Version of Material and Measures \\ Measures of Executive Functions}

We used the digital version of the same neuropsychological tests (WCST, Go/No-go tasks planning: Tower of Hanoi, selective attention: Trail Making test Part A-B) to measure the same executive capacities (inhibition controls, selective attention, planning, mental flexibility) in French and Syrian samples. For Arabic-version of the used tests all the French instructions were changed and replaced by Arabic ones.

Scoring was the same and based on the time spent to accomplish each tests under each condition, except for The Wisconsin Card Sorting. The order of tests and tasks was also the same (The Wisconsin Card Sorting and Go/No-go tasks followed by Tower of Hanoi task and The Trail Making test part A-B).

The presentation of the digitized version of the tests, collection of responses, and latency of the responses were controlled and recorded by an IBM compatible computer.

\section{Measures of Dispositional and Situational Anxiety Tendencies}

The validated and standardized Syrian-version of the State-Trait-Anxiety Scales (STAI-T, STAI-S Anxiety scales; 140) was developed by Amtanios (2003). The Cronbach's alpha estimated of internal consistency of the Syrian version for the Anxiety Scales was high [147], and in line with the reliability data provided by literature ( $\alpha=0.88$ for the Trait-Anxiety and $\alpha=0.86$ for the State-Anxiety Scales). In the case of the present research, internal reliability (Cronbach's alphas) was high ( $\alpha=0.92$ for the Trait-Anxiety and $\alpha=0.97$ for the State-Anxiety Scales), and closed to those observed by Amtanios (2003).

\section{Measures of Dispositional and Situational Aggressive Tendencies}

Given the lack of a validated Syrian-version of the APQ, one study was conducted with 60 (30 male and 30 female) Syrian students from Tichreen University in Syria in order to develop a Syrian version of the APQ, and examine its psychometric properties. Four bilingual (French-Arab) professors from Tichreen University in Syria took part in development of Syrian-version of the 24-items of the APQ. Two out of four were informed experts and translated all the items from French to Arabic language, and two others were non-informed experts only in charge to back-translation procedure (from Arabic language to French). Each version was then reviewed and compared with another version after being back-translated by the native Arabic-Speaking author. The finalized Arabic version of the APQ was administered to 60 Syrian students ( $50 \%$ female) in order to examine its psychometric properties (internal reliability). Given critical condition of the country, we were not able to verify its test-retest reliability. The analyses of data for 60 Syrian students who agreed to complete the questionnaire showed in line with the reliability data provided by O'Connor and his colleagues (anger $=0.94$ ) high internal reliability (Cronbach's alphas) for anger emotional subscale specifically for females participants. In addition, the results showed that the APQ-anger subscale measures were positively correlated with the APQ's $(a=0.86)$ measure of aggressive reaction $(r=55)$. These results were in line with the reliability data observed for our French sample (anger $a=0.89$, Anger-aggression $r=0.56$ ), too. Therefore, internal reliability validity of the APQ-anger subscale is acceptable and in the predicted direction.

\subsubsection{Procedure}

After having been introduced to the experimental box, the participants were invited to sit in a chair facing a uniformly gray computer screen. The experimenter adjusted a headphone to the participant's head. All experimen- 
tal instructions were transmitted via the headphone to the participant. After having been informed of the apparent goals of the experiment, participants read and signed the first part of an informed consent form. Then, during a first session (20 - 30 minutes), they completed a questionnaire measuring aggressive (12-items APQ) and anxiety (STAI-Trait) tendencies. In the second experimental session (30 - 45 minutes) participants performed the executive tests and filling out the questionnaire measuring aggressive (12-items APQ) and anxiety (STAI-state) tendencies. At the end of the second experimental session, participants were asked to indicate on a 4-point intensity scales ranging from 0 (not at all) to 4 (extremely) the extent to which they were disturbed by noise during completion of experimental tasks. Then after, they probed for suspicion and skepticism, but none reported knowledge of the study's purpose. Finally, they signed the second part of an informed consent form before being thoroughly debriefed and thanked.

\subsection{Statistical Analyses}

Given small sample size and study's design (Gender x Nationality (experience of War) X Experimental stimulation) we performed factorial analyses of variance on our data. For each comparative study, before testing our correlative and causal hypotheses, participants' scores on noise disturbance scale were analyzed in order to verify the effect of experimental stimulation using a $2 \times 2 \times 2$ (Gender x Nationality (experience of War) X Experimental stimulation) ANOVA was used. Then we analyzed relationship between impaired executive performances and negative reactivity, in order to test our correlative hypothesis, and after we used a $2 \times 2 \times 2$ (Gender $\mathrm{x}$ Nationality (experience of War) X Experimental stimulation) ANOVA in order to verify our causal hypotheses.

\section{Results}

\section{France-Syria Comparative Study}

\section{Experimental Condition Check}

Participants' scores on noise disturbance scale were analyzed using a $2 \times 2 \times 2$ (Gender x Nationality X Experimental stimulation) ANOVA in order to verify the effect of experimental stimulation. Analysis of ratings revealed a significant second order interaction between nationality and gender of the participants, $F 1,112=$ 188.45, $p<0.000, \eta^{2}=0.63$, and two main effects of Experimental condition, $F 1,112=4.80, p<0.03, \eta^{2}=$ 0.04 , and gender, $F 1,112=18.22, p<0.000, \eta^{2}=0.14$. Configuration of the data for main effects revealed the highest felt disturbance score for participants in aversive condition $(M=2.43 \mathrm{vs.} M=0.36)$, and for women $(M$ $=1.66$ vs. $M=1.05$ ). Effect of interaction correspond to the highest disturbance felt by women, specifically French ones (French: Mwomen $=1.80$ vs. Mmen $=0.86$ vs. Syrian: Mwomen $=1.53$ vs. Mmen $=1.23$ ). Thus, experimental manipulation produced groups that differed substantially in their average felt disturbance induced by aversive stimulation.

\section{Relationship between Impaired Executive Performances and Negative reactivity}

As shown in Table 3, for the all participants the measures of negative reactivity (aggressive and anxiety tendencies) were positively correlated with impaired performance on the executive function tests. More time was observed for more angry and more aggressive individuals. However, regarding anxiety tendencies, only state of anxiety induced by experimental condition were highly and significantly correlated with impaired executive performances. Therefore our results for both samples are consistent with those reported in existing literature, and confirm those we found in the case of our last research and our pilot study. In sum, consistent with our correlational hypothesis, higher executive scores (higher performance on perseveration, planning, attention, inhibition, and mental flexibility) were observed for non-aggressive individuals before and after experimental manipulation. These tendencies were observed for anxiety after exposing participant to experimental stimulation.

Separate analyses for participants under neutral condition and those under aversive condition revealed mostly positive correlations between the measures of negative reactivity and impaired executive performance, for French as well as Syrian samples.

\section{Effects of Experimental Conditions on Negative Reactivity (Aggressive and Anxiety Tendencies) and Ex-} ecutive Performances

In the case of French-Syrian Comparative Study, in order to verify our causal hypotheses related to negative reactivity and executive performances, we analyzed the data related to executive performance participants, using a $2 \times 2 \times 2$ factorial analysis (Gender x Nationality x Experimental stimulation). For negative reactivity, we 
Table 3. Inter-correlations between executive performance and negative reactivity for all participants.

\begin{tabular}{|c|c|c|c|c|c|c|c|c|c|c|c|c|}
\hline & 1 & 2 & 3 & 4 & 5 & 6 & 7 & 8 & 9 & 10 & 11 & 12 \\
\hline 1.Perseveration (WSCT) & 1.00 & & & & & & & & & & & \\
\hline 2. Attention (Go) & 0.37 & 1.00 & & & & & & & & & & \\
\hline 3. Inhibition (No-Go) & 0.27 & 0.28 & 1.00 & & & & & & & & & \\
\hline 4. Planning (Hanoi) & 0.49 & 0.20 & 0.28 & 1.00 & & & & & & & & \\
\hline 5. Attention (TMTA) & 0.29 & 0.09 & 0.15 & 0.45 & 1.00 & & & & & & & \\
\hline 6. Inhibition (TMTB) & 0.40 & 0.20 & 0.30 & 0.35 & 0.35 & 1.00 & & & & & & \\
\hline 7. Anxiety-State (STAI) & 0.46 & 0.21 & 0.19 & 0.67 & 0.39 & 0.42 & 1.00 & & & & & \\
\hline 8. Anxiety-Trait (STAI) & 0.00 & 0.15 & 0.08 & 0.07 & 0.06 & 0.11 & 0.17 & 1.00 & & & & \\
\hline 9. Anger (APQB) & 0.22 & 0.08 & 0.03 & 0.28 & 0.22 & 0.22 & 0.19 & 0.05 & 1.00 & & & \\
\hline 10. Anger (APQA) & 0.13 & 0.09 & 0.07 & 0.20 & 0.05 & 0.13 & 0.20 & 0.03 & 0.58 & 1.00 & & \\
\hline 11.Aggression (APQB) & 0.51 & 0.31 & 0.17 & 0.57 & 0.37 & 0.33 & 0.62 & 0.15 & 0.25 & 0.24 & 1.00 & \\
\hline 12.Aggression (APQA) & 0.31 & 0.11 & 0.02 & 0.27 & 0.14 & 0.03 & 0.29 & 0.09 & 0.25 & 0.47 & 0.37 & 1.00 \\
\hline
\end{tabular}

Note: $r>0.18$ are significant at $p<0.05$.

analyzed and compared directly the data from the first to the second experimental sessions. We conducted separate analyses of variance on anger and aggressive scores on the APQ's subscales. Same analyses were conducted for verifying the difference between two experimental sessions on anxiety tendencies, too. In both case, we used a $2 \times 2 \times 2 \times 2$ factorial analysis (Gender x Nationality x Experimental stimulation x Experimental session), in which the latter factor was treated as repeated-measures.

\section{Analyses of Executive Performance in Function of Experimental Conditions}

In order to evaluate the effect of experimental condition on executive performances, we used a $2 \times 2 \times 2$ factorial analysis (Gender $\mathrm{x}$ Nationality $\mathrm{x}$ Experimental condition). Analyses of variance on executive performances indicated significant main effects of experimental stimulation for all scores related to impaired executive controls, in terms of perseveration (WSCT), $F(1,112)=86.76, p=0.000$, inhibition (No-Go), $F(1,112)=$ 16.78, $p=0.001$, planning (Hanoi Tower), $F(1,112)=44.77, p=0.000$, mental flexibility (TMTB), $F(1,112)$ $=55.77, p=0.000$, attention $(\mathrm{Go}): F(1,112)=14.49, p=0.001$, TMTA, $F(1,112)=47.19, p=0.000$. In all cases, compared to neutral condition, under the aversive stimulation participants' performance were worse, taking longer executive times for completion all executive tasks (see Table 4). Analyses of variance revealed significant main effects of gender on inhibition (TMTB), $F(1,112)=6.88, p=0.01$, and attention (TMTA), $F(1$, $112)=5.53, p=0.02$, too. Regarding this last capacity, analyses revealed significant interaction effect involving participants' gender and nationality, $F(1,112)=14.79, p=0.001$, too. The significant effects involving gender for inhibition were expressed in terms of an increased in time decisions for women under the aversive stimulation (respectively Mwomen $=103.633 \mathrm{~ms}$ vs. Mmen $=89.275 \mathrm{~ms}$ ). Regarding capacity of attention, configuration of the data showed shorter time decision for French participants, specifically for men (respectively French sample: Mmen $=33.326$ ms vs. Mwomen = $37.441 \mathrm{~ms}$; Syrien sample: Mmen $=49.246$ ms vs. Mwomen = $35.043 \mathrm{~ms}$ ).

\section{Analyses of Aggressive Tendencies}

Analyses of the APQ-anger scores before and after completion of experimental tasks showed a second order interaction between experimental sessions with participants' gender, $F(1,112)=7.14, p<0.01, \eta^{2}=0.059$. A third order significant interaction involving experimental sessions, experimental conditions, and participants' nationality were found, too, $F(1,112)=6.68, p<0.02, \eta^{2}=0.056$. For the interaction involving experimental sessions and participants' gender, the results indicated higher felt anger in women after and for men before accomplishment of experimental tasks (women Before $M=29.72$ vs. After $M=32.02$; Men Before $M=32.65$ vs. After $M=30.90$ ). In the case of third order significant interaction involving experimental sessions, experimental conditions, and participants' nationality, the results showed the highest levels of felt anger after completion the 
Table 4. Mean executive performance scores and standard deviations, by experimental condition $(\mathrm{N}=120)$.

\begin{tabular}{ccccccc}
\hline Effet Simple & $M(S D)$ & $M(S D)$ & dl & $F$ & $p$ & $\eta^{2}$ \\
\hline & Aversive condition (noise of $80 \mathrm{db})$ & Neutral condition & & & & \\
\hline Perseveration (WSCT) & $5.78(0.93)$ & $17.97(0.93)$ & 1,112 & 86.76 & 0.000 & 0.45 \\
Inhibition (No-Go) & $99,046(2383)$ & $12203(3602)$ & 1,112 & 16.78 & 0.000 & 0.13 \\
Planification (Hanoi) & $22.60(8.05)$ & $36.73(14.19)$ & 1,112 & 44.77 & 0.000 & 0.28 \\
Flexibilité (TMTB) & $76,015(2624)$ & $116899(3454)$ & 1,112 & 55.77 & 0.000 & 0.33 \\
Attention (TMT A) & $31,395(1172)$ & $46133(1464)$ & 1,112 & 47.19 & 0.000 & 0.30 \\
Attention (Go) & $78,452(1764)$ & $126612(9482)$ & 1,112 & 14.49 & 0.000 & 0.11 \\
\hline
\end{tabular}

Note: Measurement unites for Executive performances are expressed in Millisecond.

experimental tasks, specifically for French participants (French: Neutral condition Before $M=32.47$, After $M=$ 32.03 vs. Aversive condition Before $M=36.77$, After $M=37.57$; Syrian: Neutral condition before $M=25.50$, after $M=29.17$ vs. Aversive condition Before $M=30.00$ after $M=27.07$ ).

Separate analyses of variance on APQ-anger scores for all participants after completion of the experimental task indicated significant interaction effect of experimental condition and participants' nationality, $F(1,112)=$ 4.95; $p<0.03, \eta^{2}=0.04$, supported by a main effect involving participants' nationality, $F(1,112)=15.17 ; p<$ $0.000, \eta^{2}=0.12$. Consistent with our hypothesis, Syrians participants significantly expressed higher level of anger $(M=34.80$ vs. $M=28.11)$, specifically under aversive experimental condition $(M=37.57$ vs. $M=32.03)$. These tendencies reversed in the case of French sample. In general, French participants significantly expressed more anger under neutral condition $(M=29.17$ vs. $M=27.07)$.

Same analyses for aggressive choices showed significant a main effect of experimental sessions, $F(1,112)=$ 15.09, $p=0.0001, \eta^{2}=0.12$, with more frequent aggressive choices after completion of experimental tasks $(M=$ 0.202 vs. $M=0.133$ ). In addition, two second order interaction effects between experimental sessions with participants' gender, $F(1,112)=6.51, p=0.02, \eta^{2}=0.055$, on one hand and on the other hand, with experimental conditions, $F(1,112)=5.73, p=0.02, \eta^{2}=0.048$. The interaction effect involving experimental sessions and participants' gender indicated more frequent aggressive choices after completion of experimental tasks, specifically by women (Women Before $M=0.128$ vs. After $M=0.242$; Men Before $M=0.137$ vs. $M=0.161$ ). The interaction between experimental sessions and experimental conditions showed that participants chose more frequently aggressive responses after completion the experimental tasks, specifically under aversive stimulation (Neutral condition Before $M=0.053$, After $M=0.164$ vs. aversive condition Before $M=0.213$ After $M=0.239$ ).

Consistent with our hypothesis, separate analyses for data after completion of experimental tasks showed Syrian participants chose more frequently than French counterparts aggressive responses, particularly under aversive condition (Mean frequency respectively for Syrians under aversive condition (aversive condition $M=4.17$ vs. Neutral condition $M=2.20$ ), reversed tendencies were observed for French participants (aversive condition $M=1.57$ vs. Neutral condition $M=1.73$ ).

Inspection of the data for interaction involving experimental condition and participants' gender showed that the most frequent aggressive responses for women than men, specifically under aversive condition (Women under aversive condition $M=2.93$ vs. under Neutral condition $M=2.87$; Men under aversive condition $M=2.80$ vs. under Neutral condition $M=1.07$ ).

\section{Analyses of Anxiety Tendencies}

Analyses of the anxiety tendencies before and after completion of experimental tasks revealed main significant effect of experimental session, $F(1,112)=20.77, p<0.000, \eta^{2}=0.16$. In all cases, compared to the first session, during second session participants expressed higher level of felt anxiety ( $M=44.25$ vs. $M=39.87)$. In addition, analyses showed two second order interaction between experimental sessions with experimental conditions, $F(1,112)=82.45, p<0.000, \eta^{2}=0.42$, on one hand and on the other hand, with participants' gender, $F$ $(1,112)=7.31, p<0.008, \eta^{2}=0.06$. The third order significant interaction involving experimental sessions, experimental conditions, and participants' nationality were found, too, $F(1,112)=31.72, p<0.000, \eta^{2}=0.22$. For the interaction involving experimental sessions and experimental conditions, the results showed the highest scores of State-anxiety, specifically under aversive stimulation (Neutral condition Trait-Anxiety $M=39.37$, 
State-anxiety $M=35.02$; aversive stimulation condition Trait-Anxiety $M=40.37$, State-anxiety $M=53.48$ ). Regarding interaction between experimental sessions and participants' gender, inspection of the data revealed higher level of anxiety state for the both sexes, specifically for women (Women Trait-Anxiety $M=39.30$, Stateanxiety $M=46.20$, Men Trait-Anxiety $M=40.50$, State-anxiety $M=42.30$ ). In the case of third order significant interaction involving experimental sessions, experimental conditions, and participants' nationality, the results indicated the higher level of state anxiety under aversive stimulation, specifically for French participants (Syrian: Neutral condition Trait-Anxiety $M=36.43$ State-anxiety $M=38.67$ vs. Aversive condition Trait-Anxiety $M=$ 38.03, State-anxiety $M=46.90$; French: Neutral condition Trait-Anxiety $M=42.30$, State-anxiety $M=31.37$ vs. Aversive condition Trait-Anxiety $M=42.70$, State-anxiety $M=60.07$ ).

Separate analyses of variance on Trait-Anxiety scores indicated a main effect of participants' nationality, $F$ (1, $112)=7.74, p<0.006$, with higher level of anxiety for Syrian participants $(M=42.47$ vs. $M=37.23)$. Same analyses on State-anxiety score revealed two interaction effects between participants' nationality with experimental condition, $F(1,112)=89.87, p=0.000, \eta^{2}=0.45$, on one hand and on the other hand, with participants' gender, $F(1,112)=20.48, p<0.000, \eta^{2}=0.15$. These interaction effects were supported by main effects of experimental condition, $F(1,112)=295.36, p<0.000, \eta^{2}=0.73$ (Aversive condition $M=53.75$ vs. Neutral condition $M=35.01$ ); participants' nationality: $F(1,112)=7.74, p<0.006, \eta^{2}=0.06$ (Syrians $M=60.43$ vs. Frenches $M=47.06$ ), and their gender, $F(1,112)=13.02, p<0.0005, \eta^{2}=0.11$ (Women $M=46.35$ vs. Men $M$ $=42.41$ ).

Inspection of the data related to interaction between experimental condition and participants' nationality showed that after completion of experimental tasks, Syrian participants were more anxious than their French counterparts, specifically in the case of the aversive condition (Syrians aversive condition $M=60.43$ vs. Neutral condition $M=31.36$; Frenches aversive condition $M=47.06$ vs. Neutral condition $M=38.66$ ).

Configuration of the data regarding interaction between Experimental condition and participants' Gender revealed that although after completion of experimental tasks, Syrian participants were more anxious than their French counterparts, these tendencies were more noticeable for male Syrians than female ones (Men $M=46.40$ vs. Women $M=45.40$ ), with a reversed tendencies for French participants (Men $M=38.43$ vs. Women $M=$ 47.30).

In general, analyses of our data allowed confirmation of correlative as well as causal hypotheses. The results of this comparative study are informative regarding important issues. Consistent with existing literature, we found evidence of a positive relationship between poor executive functioning and aggressive as well as anxiety tendencies, specifically for our Syrian sample living highly stressful condition in their country. Some individuals' behaviour seem to be chronically influenced by impulsive processes the way participants' behavior were influenced in the neutral condition of the present research, independent of any experimental manipulations. However, our results showed the same relation, in terms of situational or contextual control resource for participants completing experimental tasks under aversive condition. Thus, the relations of different executive processes and behavioral adjustment under aversive condition were not due solely to the individual dispositional differences. As predicted, it appears that increases in impulsiveness (anger and aggressive choices) due to aversive experimental condition were concomitant with an inability to focus individuals' attention on ongoing tasks (such as decreased performance in Trait Making Test, Tower of Hanoi, Go task), and thus were related to diminished inhibition control of task-irrelevant information (such as decreased performance in Stroop, WCST, No-go task).

\section{Syria-Syria Comparative Study}

Experimental Condition Check Participants' scores on noise disturbance scale were analyzed using a $2 \times 2 \times 2$ (Gender $\mathrm{x}$ Experience of War X Experimental stimulation) ANOVA in order to verify the effect of experimental stimulation. Analysis of ratings revealed a significant two main effects of Experimental condition, $F 1,112=$ 43.52, $p<0.000, \eta^{2}=0.49$, and Experience of War, $F 1,112=9.60, p<0.002, \eta^{2}=0.17$, with the highest felt disturbance score for participants in aversive condition $(M=3.11$ vs. $M=1.39)$, and those directly exposed to War $(M=2.67$ vs. $M=1.84)$. Thus, experimental stimulation produced groups that differed substantially in their average felt disturbance induced by aversive stimulation.

\section{Relationship between Impaired Executive Performances and Negative reactivity}

As shown in Table 5, in the case of Syrian-Syrian comparative Study also for the all participants the measures of negative reactivity, specifically aggressive tendencies (felt Anger and Aggressive choice) were positively correlated with impaired performance on the executive function tests. More time was observed for more angry and more aggressive individuals. However, regarding anxiety tendencies, only State of anxiety induced by expe- 
Table 5. Inter-correlations between executive performance and negative reactivity for all Syrian participants $(\mathrm{N}=60)$.

\begin{tabular}{|c|c|c|c|c|c|c|c|c|c|c|c|c|}
\hline Measures & 1 & 2 & 3 & 4 & 5 & 6 & 7 & 8 & 9 & 10 & 11 & 12 \\
\hline 1. Perseveration (WSCT) & 1.00 & & & & & & & & & & & \\
\hline 2. Attention (Go) & 0.40 & 1.00 & & & & & & & & & & \\
\hline 3. Inhibition (No-Go) & 0.41 & 0.46 & 1.00 & & & & & & & & & \\
\hline 4. Planning (Hanoi) & -0.05 & 0.26 & 0.12 & 1.00 & & & & & & & & \\
\hline 5. Attention (TMTA) & 0.29 & 0.51 & 0.33 & 0.32 & 1.00 & & & & & & & \\
\hline 6. Inhibition (TMTB) & 0.22 & -0.33 & -0.01 & -0.03 & 0.05 & 1.00 & & & & & & \\
\hline 7. Anxiety-State (STAI) & 0.11 & -0.19 & 0.08 & 0.12 & -0.04 & 0.28 & 1.00 & & & & & \\
\hline 8. Anxiety-Trait (STAI) & -0.37 & 0.04 & 0.17 & 0.09 & 0.05 & -0.11 & -0.11 & 1.00 & & & & \\
\hline 9. Anger (APQB) & 0.27 & 0.27 & 0.25 & 0.13 & 0.25 & 0.14 & -0.10 & -0.02 & 1.00 & & & \\
\hline 10. Anger (APQA) & 0.51 & 0.63 & 0.48 & 0.02 & 0.38 & -0.03 & -0.13 & 0.03 & 0.29 & 1.00 & & \\
\hline 11. Aggression (APQ-B) & 0.31 & 0.25 & 0.29 & 0.47 & 0.53 & 0.38 & 0.18 & 0.01 & 0.25 & 0.24 & 1.00 & \\
\hline 12. Aggression (APQ-A) & 0.33 & 0.40 & 0.39 & 0.12 & 0.18 & -0.22 & -0.11 & -0.22 & 0.09 & 0.34 & 0.14 & 1.00 \\
\hline
\end{tabular}

Note: $r>0.26$ are significant at $p<0.05$.

rimental condition were highly and significantly correlated with impaired executive performances in terms of inhibition (TMTB, $r=0.26, p<0.05$ ), for Trait anxiety correlation we observed significant but negative correlation with capacity of perseveration $(r=-0.37, p<0.05)$. Therefore our results for both samples are partially consistent with those reported in existing literature, and confirm those we found in the case of our French-Syrian Comparative as well as our pilot study. In sum, consistent with our correlational hypothesis, higher executive scores (higher performance on perseveration, planning, attention, inhibition, and mental flexibility) were observed for non-aggressive individuals. These tendencies were observed for State anxiety related to inhibition (TMTB) after exposing participant to experimental stimulation, reversed tendencies were found in the case of Trait-Anxiety and perseveration capacity. However, given small sample size $(n=60)$ and characteristics of our samples, these results should be considered with some reserves.

Separate analyses for participants under neutral condition and those under aversive condition revealed mostly positive correlations between the measures of negative reactivity and impaired executive performance, for all participants.

Effects of Experimental Conditions on Negative Reactivity (Aggressive and Anxiety Tendencies) and Executive Performances

In order to verify our causal hypotheses related to negative reactivity and executive performances in the case of participants directly or indirectly exposed to extreme stressful condition (Syrian Civil War), we analyzed the data related to executive performance, using a $2 \times 2 \times 2$ factorial analysis (Gender $\mathrm{x}$ War experience $\mathrm{x}$ Experimental stimulation). For negative reactivity, we analyzed and compared directly the data from the first to the second experimental sessions. We conducted separate analyses of variance on anger and aggressive scores on the APQ's subscales. Same analyses were conducted for verifying the difference between two experimental sessions on anxiety tendencies, too. In both case, we used a $2 \times 2 \times 2 \times 2$ factorial analysis (Gender x War experience $\mathrm{x}$ Experimental stimulation $\mathrm{x}$ Experimental session), in which the latter factor was treated as repeatedmeasures.

\section{Analyses of Executive Performance in function of Experimental Conditions}

In order to evaluate the effect of experimental conditions on executive performances, we used a $2 \times 2 \times 2$ factorial analysis (Gender x Experience of War x Experimental condition). Analyses of variance indicated significant main effects of participants' experience of war for all scores related to impaired executive controls, in terms of perseveration (WSCT), $F(1,52)=2138, p<0.000, \eta^{2}=0.26$, inhibition (No-Go), $F(1,52)=157.89, p$ $<0.000, \eta^{2}=0.73$, planning (Hanoi Tower), $F(1,52)=4.39, p<0.04, \eta^{2}=0.07$, mental flexibility (TMTB), $F$ $(1,52)=21.46, p<0.000, \eta^{2}=0.27$, attention $(\mathrm{Go}): F(1,52)=157.90, p<0.000, \eta^{2}=0.73$, TMTA, $F(1,52)=$ 
15.40, $p<0.001, \eta^{2}=0.20$. In all cases, compared to participants experiencing indirectly warfare, executive performance of those experiencing directly War were worse, taking longer executive times for completion all executive tasks (see Table 6).

Analyses of variance revealed significant main effects of gender on attention capacities as measured by TMTA, $F(1,52)=14.97, p<0.000, \eta^{2}=0.20$ as well as by Go task, $F(1,52)=5.88, p<0.01, \eta^{2}=0.09$, with shorter time decisions for women (see Table 6).

\section{Analyses of Aggressive Tendencies}

Analyses of the APQ-anger scores before and after completion of experimental tasks showed a second order interaction between experimental sessions with participants' gender, $F(1,52)=18.36, p<0.000, \eta^{2}=0.26$, supported by a main effects involving experience sessions, $F(1,52)=10.90, p<0.001, \eta^{2}=0.17$. The results indicated higher felt anger in women before and in men after completion of experimental tasks (women Before $M=28.08$ vs. After $M=26.91$; Men Before $M=32.44$ vs. After $M=41.51$ ). The configuration of the data for a third order interaction involving experimental sessions, experience of War, and participants' gender, helped to better understand these tendencies, $F(1,52)=3.84, p<0.06, \eta^{2}=0.07$. The results showed the highest levels of felt anger after completion the experimental tasks, for all participants experiencing indirectly the warfare (Women Before $M=25.30$, after $M=27.50$ vs. Men Before $M=30.69$ after $M=38.44$ ). However, these tendencies reversed for women (not for men) arriving in France after outbreak of the War (Women Before $M=$ 30.84, After $M=26.31$ vs. Men Before $M=34.18$, After $M=44.57$ ).

Separate analyses of variance for felt anger after completion of experimental tasks indicated significant main effects of experience of warfare, $F(1,52)=6.93 ; p<0.01, \eta^{2}=0.12$, and participants' gender, $F(1,52)=51.11$, $p<0.000, \eta^{2}=0.49$, with higher felt anger for Syrian participants experiencing directly warfare, $(M=33.98 \mathrm{vs}$. $M=30.48)$, on one hand and on the other hand, for men, $(M=36.98$ vs. $M=27.48)$.

Analyses of the APQ-aggressive scores before and after completion of experimental tasks showed two second order interaction effects between experimental sessions with experience of War, $F(1,52)=37.47, p=0.000, \eta^{2}$ $=0.42$, on one hand and on the other hand, with participants' gender, $F(1,52)=4.81, p=0.04, \eta^{2}=0.08$. The interaction involving experimental sessions and experience of War showed that participants experiencing directly warfare (arriving in France after outbreak of war) chose more frequently aggressive responses before completing the experimental tasks (Before $M=0.309$, After $M=0.185$ ), reversed tendencies were observed for those experiencing war indirectly (arriving in France before breakout of the War $M=0.050$ vs. After breakout of the War $M=0.178$ ). The interaction effect involving experimental sessions and participants' gender indicated for women more frequent aggressive choices before than after completion of experimental tasks (Before $M=$ 0.158 vs. After $M=0.115$ ), reversed tendencies were found for men (Before $M=0.201$ vs. $M=0.248$ ).

Separate analyses for aggressive choices after completion of experimental tasks showed significant main effects of experience of warfare, $F(1,52)=43.16, p=0.0001, \eta^{2}=0.40$ and participants' gender, $F(1,52)=14.76$,

Table 6. Mean executive performance scores and standard deviations, by participants' experience of War and their gender $(\mathrm{N}=60)$.

\begin{tabular}{|c|c|c|c|c|c|c|}
\hline Main Effects & $M(S D)$ & $M(S D)$ & dl & $F$ & $p$ & $\eta^{2}$ \\
\hline & Indirect Experience of War & Direct Experience of War & & & & \\
\hline Perseveration (WSCT) & $4.60(3.26)$ & $9.93(5.40)$ & 1,52 & 21.38 & 0.000 & 0.26 \\
\hline Inhibition (Go) & $79008(2345)$ & $182,738(3864)$ & 1,52 & 157.9 & 0.000 & 0.73 \\
\hline Planning (Hanoi) & $21.93(6.18)$ & $27.46(13.06)$ & 1,52 & 4.39 & 0.04 & 0.07 \\
\hline Mental Flexibility (TMTB) & 80416 (2915) & $122,700(4059)$ & 1,52 & 21.46 & 0.000 & 0.27 \\
\hline Attention (TMT A) & 34963 (1192) & 49,236 (1595) & 1,52 & 15.40 & 0.000 & 0.20 \\
\hline \multirow[t]{2}{*}{ Attention (Go) } & 79008 (2345) & 182,738 (3864) & 1,52 & 157.9 & 0.000 & 0.73 \\
\hline & Women & Men & & & & \\
\hline Attention (TMT A) & 35043 (1213) & 49,156 (1586) & 1,52 & 14.97 & 0.00 & 0.20 \\
\hline Attention (Go) & 11247 (54069) & $14,927(6312)$ & 1,52 & 5.88 & 0.01 & 0.09 \\
\hline
\end{tabular}

Note: Measurement unites for Executive performances are expressed in Millisecond. 
$p=0.001, \eta^{2}=0.22$, with higher aggressive choices for participants experiencing directly warfare $(M=0.248$ vs. $M=0.114)$, and for men $(M=0.224$ vs. $M=0.137)$.

Consistent partially with our hypothesis, analyses for data showed men reported more negative reactivity than women (more anger and more aggressive responses) after completion the experimental tasks, specifically those experiencing directly warfare (arriving in France after outbreak of war).

\section{Analyses of Anxiety Tendencies}

Analyses of the anxiety tendencies before and after completion of experimental tasks revealed main significant effect of experimental session, $F(1,52)=26.06, p<0.000, \eta^{2}=0.34$. In all cases, compared to the first session, during second session participants expressed lower level of State anxiety ( $M=36.07$ vs. $M=43.07)$.

Separate analyses of variance on Trait-Anxiety scores indicated no significant effect. However, analyses of the data related to State anxiety after completion of experimental tasks revealed a significant main effect related to participants' experience of War, $F(1,52)=4.56, p<0.04$, with higher level of anxiety state for Syrian participants directly experiencing warfare (arriving in France after outbreak of War; $M=37.67$ vs. $M=34.46$ ). No other significant effects had been observed.

The case of Syrians living in France is of particular importance for our researcher because of their direct vs. indirect ongoing experience of extreme stressful situation that might be associated with extreme depletion of executive capacities as well as highest aggressive tendencies given their need to cope with extreme conflict situations. According to studies published to date, many of the anxiety symptoms can be seen as a direct result of exposition to stressful situations. In sum, in case of second comparative study, consistent with our correlational hypothesis, higher executive scores (higher performance on perseveration, planning, attention, inhibition, and mental flexibility) were observed for non-aggressive individuals. These tendencies were observed for State anxiety related to inhibition (TMTB) after exposing participant to experimental stimulation. Our data confirmed partially our hypothesis related to gender differences in negative reactivity, with men reporting more negative reactivity than women (more anger and more aggressive responses) after completion the experimental tasks, specifically those experiencing directly warfare (arriving in France after outbreak of war). However, given small sample size $(n=60)$ and characteristics of our samples, these results should be considered with some reserves.

\section{Discussion and Conclusion}

The results of these studies are informative regarding important issues. Consistent with existing literature, we find evidence of a positive dispositional relationship between poor executive functioning and negative reactivity. Some individuals' behaviours seem to be chronically influenced by impulsive processes; the way participants' behaviors are influenced in the first assessment of the present research, independent of any experimental manipulations. Second, our results show the same relation, in terms of situational or contextual control resource after our participants completed executive tasks under aversive/neutral condition. Thus, the relations of different executive processes and behavioral adjustment at the second assessment are not due solely to the individual dispositional differences. As predicted, it appears that increases in impulsiveness (negative emotionality and aggressive choices) due to aversive condition are concomitant with an inability to focus individuals' attention on ongoing tasks (such as decreased performance in Trait Making Test, Tower of Hanoi, Go task), and thus are related to diminished inhibition control of task-irrelevant information (such as decreased performance in WCST, No-go task). For our Syrian sample, for example, we observe a concomitant increase of aggressive choices and decrease of executive capacities such as planning, attention, and flexibility, after completion experimental tasks under aversive condition. More interesting, our results relate to aggressive tendencies and executive performances in Syrian participants, experiencing directly or indirectly warfare, confirm the important role of the social and environmental contexts in efficient behavioral adjustment and regulation.

Regarding gender-related hypothesis, in spite of a general tendencies corresponding to more aggressive behavioral intention and higher emotional negativity in men than women, as predicted we find more emotional negativity in women and more aggressive behavioral intention in men after completion the experimental tasks under aversive stimulation. Unique gender-related difference in cognitive ability observed in the case of the last study is related to the attention, with women scoring higher than men on the attention section of the TMT and Go tasks.

However, the extent of these differences and their relation to the adjustment behavior remain to be further understood, and merit further investigations. More research is needed for testing these differences taking into 
account other emotional and executive characteristics of individuals. The findings of the current research suggest that different aspects of executive control are likely to play an important role in self-regulation across different contexts. As expected, our studies indicate that increases in impulsiveness due to aversive noise, as one of the aspects of threatening contexts, may be concomitant with an inability to voluntarily turn one's attention away from the adverse characteristics of possible conflict, and thus may be related to diminished inhibition control of task-irrelevant information. Moreover, these relations seem to be contextually moderated by anger. That is proneness to anger heightens individuals' vulnerability to behavioral problems, depending on contextual characteristics. Therefore, it is assumed that anger contextually moderates relations of executive controls (voluntarily or reactive controls) and behavioral problems. Yet, our findings suggest that the contributions of selfregulatory processes such as executive controls to adjustment are more multifaceted and complex than having been acknowledged.

In summary, our finding suggests that executive control considered as inhibition of unwanted thought, initiation/planning new actions, and being selectively attentive, are jointly implicated in regulation of emotional behaviors such as aggression. In addition, the affective context influenced the level of these executive controls. While a negative context interfered significantly with participants' performance and fostered aggressive feelings and actions, a positive or neutral context resulted in a better executive performance and less aggressive tendencies, [132]. This fact may in part explain why individuals who grow in adverse social and environmental contexts might develop poor executive capacities, and be emotionally vulnerable and more akin to aggression and antisocial behavior. Yet, even though this programming might be in place very early in development, our data showed that situational characteristics could alter individuals' sensibility and control capacities in adulthood. It seems whatever the individual's age or his/her developmental step, self-threatening context may cause a deficit in social information processing, which result in a high emotional reactivity. Thus, even though adults are supposed to control their affective experiences and shift their attention away from the negative cues related to anger, impacts of immediate self-threatening environment could alter their regulatory capacities.

However, our research has his own limits. Understanding the complex interaction effects between dispositional and situational differences in executive control of affective behaviors needs more appropriate statistical analyses, such as structural equation modeling (SEM). Our sample-size, specifically for Syrian sample living in Paris, did not allow applying those analyses. Other methodological questions subsist regarding so-called "task purity" [148], and to decisional processes involved in treatment of the text-evoked imagery. Our material lacks a pure measurement of working memory capacities. As a matter of fact, individuals experiencing negative emotional state, beset with self-doubts, might turn their attention inward and become self-preoccupied and devoted to emotional repair (searching a positive personal souvenir). In addition, conflict tasks (e.g. Stroop, No-go) require conflicting alternatives to be hold in mind [133]. Therefore, under the failure condition the working memory demands should be greater than those under the success condition, and envisioning failure scenarios easier [149]. If this analysis is correct, we would expect more anger and more aggressive tendencies whenever the working memory demands increase.

Nevertheless, researchers have scarcely begun to study this area using a series of neuropsychological tests. We believe implications of research like the one presented here is essential and a necessary step for understanding the problem that are rooted in the study of aggression and its prevention planning taking into account dispositional as well as situational characteristics. Our study allowed identification of stressful social and environmental contexts as a serious cause of poor executive performances and negative reactivity. However, our data also showed that the individuals under neutral condition performed significantly better and exhibited less negative reactivity. Thus, present research suggests the importance of contextual characteristics in dynamic relation between reactive and executive regulation of social behavior. By understanding those processes we should be in a better position to design an optimal training condition to improve executive capacities in children and adults exposed to adversity such as threatening and conflict environmental. We believe that comparative studies of the relation between affective and cognitive behavioral regulations in such cases might provide new perspectives on intervention programs in social health sectors.

\section{References}

[1] Hammen, C. (2005) Stress and Depression. Annual Review of Clinical Psychology, 1, 293-319. http://dx.doi.org/10.1146/annurev.clinpsy.1.102803.143938 
[2] Evans, G.W. and Cohen, S. (2004) Environmental Stress. Encyclopedia of Applied Psychology, 1, 815-824. http://dx.doi.org/10.1016/B0-12-657410-3/00704-2

[3] Segerstrom, S.C. and Miller, G.E. (2004) Psychological Stress and the Human Immune System: A Meta-Analytic Study of 30 Years of Inquiry. Psychological Bulletin, 130, 601-630. http://dx.doi.org/10.1037/0033-2909.130.4.601

[4] Halpern, D. (1995) Mental Health and the Built Environment. Taylor \& Francis, London, 196 p.

[5] Sucker, K., Both, K. and Winneke, G. (2009) Review of Adverse Health Effects of Odours in Field Studies. Water Science Technology, 59, 1281-1289. http://dx.doi.org/10.2166/wst.2009.113

[6] Seligman, M.E.P. (1975) Helplessness. W.H. Freeman, San Francisco.

[7] Bandura, A. (1997) Self-Efficacy. W.H. Freeman, San Francisco.

[8] Evans, G.W. and Stecker, R. (2004) Motivational Consequences of Environmental Stress. Journal of Environmental Psychology, 24, 143-165. http://dx.doi.org/10.1016/S0272-4944(03)00076-8

[9] Bell, A.P. and Fusco, M.E. (1989) Heat and Violence in the Dallas Field Data: Linearity, Curvilinearity, and Heteroscedasticity. Journal of Applied Social Psychology, 19, 1479-1482. http://dx.doi.org/10.1111/j.1559-1816.1989.tb01459.x

[10] Anderson, C.A. and Anderson, K.B. (1998) Temperature and Aggression: Paradox, Controversy, and a (Fairly) Clear Picture. In: Geen, R.G. and Donnerstein, E., Eds., Human Aggression: Theories, Research, and Implications for Social Policy, Academic Press, New York, 247-298.

[11] Bell, P.A., Greene, T.C., Fisher, J.D. and Baum, A. (2001) Environmental Psychology. 5th Edition, Harcourt College Publishers, New York.

[12] Stansfield, S.A., Clark, C. and Crombie, R. (2012) Noise. In: Clayton, S., Ed., The Oxford Handbook of Environmental and Conservation Psychology, Oxford University Press, New York, 375-390. http://dx.doi.org/10.1093/oxfordhb/9780199733026.013.0020

[13] Baker, M.A. and Holding, D.H. (1993) The Effects of Noise and Speech on Cognitive Task Performance. Journal of General Psychology, 120, 339-355. http://dx.doi.org/10.1080/00221309.1993.9711152

[14] Berglund, B., Hassmen, P. and Job, R.F. (1996) Sources and Effects of Low-Frequency Noise. The Journal of the Acoustical Society of America, 99, 2985-3002. http://dx.doi.org/10.1121/1.414863

[15] Babisch, W. (2006) Transportation Noise and Cardiovascular Risk: Updated Review and Synthesis of Epidemiological Studies Indicate That the Evidence Has Increased. Noise Health, 8, 1-29. http://dx.doi.org/10.4103/1463-1741.32464

[16] Jarup, L., Dudley, M.L., Babisch, W., Houthuijs, D., Swart, W., Pershagen, G., et al. (2005) Hypertension and Exposure to Noise near Airports (HYENA): Study Design and Noise Exposure Assessment. Environmental Health Perspective, 113, 1473-1478. http://dx.doi.org/10.1289/ehp.8037

[17] Van Kempen, E.E., Kruize, H., Boshuizen, H.C., Ameling, C.B., Staatsen, B.A. and de Hollander, A.E. (2002) The Association between Noise Exposure and Blood Pressure and Ischemic Heart Disease: A Meta-Analysis. Environmental Health Perspective, 110, 307-317. http://dx.doi.org/10.1289/ehp.02110307

[18] Babisch, W. (2000) Traffic Noise and Cardiovascular Disease: Epidemiological Review and Synthesis. Noise Health, 2, 9-32.

[19] Babisch, W., Beule, B., Schust, M., Kersten, N. and Ising, H. (2005) Traffic Noise and Risk of Myocardial Infarction. Epidemiology, 16, 33-40. http://dx.doi.org/10.1097/01.ede.0000147104.84424.24

[20] Clark, I.E., Dodson, M.W., Jiang, C., Cao, J.H., Huh, J.R., Seol, J.H., Yoo, S.J., Hay, B.A. and Guo, M. (2006) Drosophila Pink1 Is Required for Mitochondrial Function and Interacts Genetically with Parkin. Nature, 441, 1162-1166. http://dx.doi.org/10.1038/nature04779

[21] Hygge, S., Evans, G.W. and Bullinger, M. (2002) A Prospective Study of Some Effects of Aircraft Noise on Cognitive Performance in Schoolchildren. Psychological Science, 13, 469-474. http://dx.doi.org/10.1111/1467-9280.00483

[22] Haines, M.M., Stansfeld, S.A., Job, R.F.S., Berglund, B. and Head, J. (2001) Chronic Aircraft Noise Exposure, Stress Responses, Mental Health and Cognitive Performance in School Children. Psychological Medicine, 31, 265-277. http://dx.doi.org/10.1017/s0033291701003282

[23] Haines, M.M., Stansfeld, S.A., Job, R.F.S., Berglund, B. and Head, J. (2001) A Follow-Up Study of Effects of Chronic Aircraft Noise Exposure on Child Stress Responses and Cognition. International Journal of Epidemiology, 30, 839845. http://dx.doi.org/10.1093/ije/30.4.839

[24] Stephen, A., Stansfeld, S.A., Mary, M., Haines, M.M., Berry, B. and Michael Burr, M. (2009) Reduction of Road Traffic Noise and Mental Health: An Intervention Study. Noise \& Health, 11, 169-175. http://dx.doi.org/10.4103/1463-1741.53364

[25] Nurmi, J.E. and von Wright, J. (1983) Interactive Effects of Noise, Neuroticism, and State-Anxiety in the Learning and 
Recall of a Textbook Passage. Human Learning, 2, 119-125.

[26] Lercher, P., Evans, G.W., Meis, M. and Kofler, W.W. (2002) Ambient Neighbourhood Noise and Children’s Mental Health. http://oem.bmj.com/

[27] Schreckenberg, K., Camargo, I., Withnall, K., Corrigan, C., Franks, P., Roe, D., Scherl, L.M. and Richardson, V. (2010) Social Assessment of Conservation Initiatives: A Review of Rapid Methodologies. Natural Resource Issues No. 22, IIED, London.

[28] Dratva, J., Phuleria, H.C., Foraster, M., Gaspoz, G.M., Keidel, D., Künzli, N., Sally Liu, L.J., Pons, M., Zemp, E., Gerbase, M.W. and Schindler, C. (2010) Transportation Noise and Blood Pressure in a Population-Based Sample of Adults. Environmental Health Perspective, 120, 50-55. http://dx.doi.org/10.1289/ehp.1103448

[29] Melamed, S., Kushnir, T. and Shirom, A. (1992) Burnout and Risk Factors for Cardiovascular Disease. Behavioral Medicine, 18, 53-61. http://dx.doi.org/10.1080/08964289.1992.9935172

[30] Cohen, A. (1976) The Influence of a Company Hearing Conservation Program on Extra-Auditory Problems in Workers. Journal of Safety Research, 8, 146-162.

[31] Cameron, P., Robertson, D. and Zaks, J. (1972) Sound Pollution, Noise Pollution, and Health: Community Parameters. Journal of Applied Psychology, 56, 67-74. http://dx.doi.org/10.1037/h0032105

[32] Melamed, S., Ugarten, U., Shirom, A., Kahana, L., Lerman, Y. and Froom, P. (1999) Chronic Burnout, Somatic Arousal and Elevated Cortisol Levels. Journal of Psychosomatic Research, 46, 591-598. http://dx.doi.org/10.1016/S0022-3999(99)00007-0

[33] McEwen, B.S. (1998) Stress, Adaptation, and Disease. Allostasis and Allostatic Load. Annals of the New York Academic Science, 1, 33-44. http://dx.doi.org/10.1111/j.1749-6632.1998.tb09546.x

[34] Cannon, W. (1932) The Wisdom of the Body. Norton \& Company, INC., New York.

[35] Selye, H. (1956) The Stress of Life. Gallimard, Paris.

[36] Frank, D.W., Dewitt, M., Hudgens-Haney, M.E., Schaeffer, D.J., Ball, B.H., Schwarz, N.F., Hussein, A.A., Smart, L.M. and Sabatinelli, D. (2014) Emotion Regulation: Quantitative Meta-Analysis of Functional Activation and Deactivation. Neuroscience \& Biobehavioral Reviews, 45, 202-211. http://dx.doi.org/10.1016/j.neubiorev.2014.06.010

[37] Davidson, R.J., Putnam, K.M. and Larson, C.L. (2000) Dysfunction in the Neural Circuitry of Emotion Regulation-A Possible Prelude to Violence. Science, 289, 591-594. http://dx.doi.org/10.1126/science.289.5479.591

[38] Loeb, M. (1986) Noise and Human Efficacy. Wiley, Chichester, 269 p.

[39] Smith, A.P. and Broadbent, D.E. (1992) Non-Auditory Effects of Noise at Work: A Review of the Literature. HSE Contract Research Report No, 30, HMSO, London.

[40] Lazarus, R.S. (1966) Psychological Stress and the Coping Process. McGraw-Hill, New York.

[41] Gross, J.J. (2002) Emotion Regulation: Affective, Cognitive, and Social Consequences. Psychophysiology, 39, 281291. http://dx.doi.org/10.1017/S0048577201393198

[42] Lazarus, R.S. and Folkman, S. (1984) Stress, Appraisal, and Coping. Springer, New York.

[43] Lazarus, R.S. (1991) Emotion and Adaptation. Oxford University Press, London.

[44] Lazarus, R.S. (1993) Coping Theory and Research: Past, Present, and Future. Psychosomatik Medicine, 55, $234-247$. http://dx.doi.org/10.1097/00006842-199305000-00002

[45] Lazarus, R.S. (1993) From Psychological Stress to the Emotions: A History of a Changing Outlook. Annual Review of Psychology, 44, 1-21. http://dx.doi.org/10.1146/annurev.ps.44.020193.000245

[46] Lazarus, R.S. and Folkman, S. (1987) Transactional Theory and Research on Emotions and Coping. European Journal of Personality, 1, 141-170. http://dx.doi.org/10.1002/per.2410010304

[47] Gross, J.J. and Thompson, R.A. (2007) Emotion Regulation: Conceptual Foundations. In: Gross, J.J., Ed., Handbook of Emotion Regulation, Guilford Press, New York, 3-24.

[48] Gross, J.J. (1998) Antecedent- and Response-Focused Emotion Regulation: Divergent Consequences for Experience, Expression, and Physiology. Journal of Personality and Social Psychology, 74, 224-237. http://dx.doi.org/10.1037/0022-3514.74.1.224

[49] Sheppes, G., Scheibe, S., Suri, G. and Gross, J.J. (2011) Emotion Regulation Choice. Psychological Science, 22, 13911396. http://dx.doi.org/10.1177/0956797611418350

[50] Campbell-Sills, L. and Barlow, D.H. (2007) Incorporating Emotion Regulation into Conceptualizations and Treatments of Anxiety and Mood Disorders. In: Gross, J.J., Ed., Handbook of Emotion Regulation, Guilford Press, New York, 542-559.

[51] Wegner, D.M. and Zanakos, S. (1994) Chronic Thought Suppression. Journal of Personality, 62, 615-640. 
http://dx.doi.org/10.1111/j.1467-6494.1994.tb00311.x

[52] Ochsner, K.N. and Gross, J.J. (2008) Cognitive Emotion Regulation: Insights from Social, Cognitive, Affective Neuroscience. Current Directions in Psychological Science, 17, 153-158. http://dx.doi.org/10.1111/j.1467-8721.2008.00566.x

[53] Samson, A.C. and Gross, J.J. (2012) Humour as Emotion Regulation: The Differential Consequences of Negative versus Positive Humour. Cognition and Emotion, 26, 375-384. http://dx.doi.org/10.1080/02699931.2011.585069

[54] Dan-Glauser, E.S. and Gross, J.J. (2011) The Temporal Dynamics of Two Response-Focused Forms of Emotion Regulation: Experiential, Expressive, and Autonomic Consequences. Psychophysiology, 48, 1309-1322. http://dx.doi.org/10.1111/j.1469-8986.2011.01191.x

[55] Sher, K.J. and Grekin, E.R. (2007) Alcohol and Affect Regulation. In: Gross, J.J., Ed., Handbook of Emotion Regulation, Guilford Press, New York, 560-580.

[56] Vohs, K.D. and Baumeister, R.F. (2004) Ego Depletion, Self-Control, and Choice. In: Greenberg, J., Koole, S.L. and Pyszczynski, T., Eds., Handbook of Experimental Existential Psychology, Guilford Press, New York, 398-410.

[57] Forgas, J., Baumeister, R. and Tice, D. (2009) Psychology of Self-Regulation: An Introductory Review. In: Forgas, J., Baumeister, R.F. and Tice, D., Eds., Psychology of Self-Regulation: Cognitive, Affective, and Motivational Processes, Psychology Press, New York, 1-17.

[58] Posner, M.I. and Rothbart, M.K. (2004) Hebb’s Neural Networks Support the Integration of Psychological Science. Canadian Psychology/Psychologie Canadienne, 45, 265-278. http://dx.doi.org/10.1037/h0086997

[59] Oettingen, G. and Gollwitzer, P.M. (2009) Making Goal Pursuit Effective: Expectancy-Dependent Goal Setting and Planned Goal Striving. In: Forgas, J.P., Baumeister, R.F. and Tice, D.M., Eds., Psychology of Self-Regulation: Cognitive, Affective, and Motivational Processes, Psychology Press, New York, 127-146.

[60] Von Hippel, W. and Ronay, R. (2009) Executive Functions and Self-Control. In: Forgas, J.P., Baumeister, R.F. and Tice, D.M., Eds., Psychology of Self-Regulation: Cognitive, Affective, and Motivational Processes, Psychology Press, New York, 303-318.

[61] Rothbart, M.K. and Bates, J.E. (2006) Temperament. In: Damon, W. and Eisenberg, N., Eds., Handbook of Child Psychology: Volume 3, Social, Emotional, and Personality Development, 6th Edition, Wiley, New York, 105-176.

[62] Rothbart, M.K. (1989) Behavioral Approach and Inhibition. In: Reznick, J.S., Ed., Perspectives on Behavioral Inhibition, University of Chicago Press, Chicago, 139-157.

[63] Rothbart, M.K., Ahadi, S.A., Hershey, K.L. and Fisher, P. (2001) Investigations of Temperament at Three to Seven Years: The Children's Behavior Questionnaire. Child Development, 72, 1394-1408. http://dx.doi.org/10.1111/1467-8624.00355

[64] Eisenberg, N., Valiente, C., Spinrad, T.L., Cumberland, A., Liew, J., Reiser, M., Zhou, Q. and Losoya, S.H. (2009) Longitudinal Relations of Children's Effortful Control, Impulsivity, and Negative Emotionality to Their Externalizing, Internalizing, and Co-Occurring Behavior Problems. Developmental Psychology, 45, 988-1008. http://dx.doi.org/10.1037/a0016213

[65] Eisenberg, N., Spinrad, T.L., Fabes, R.A., Reiser, M., Cumberland, A., Shepard, S.A., Valiente, C., Losoya, S.H., Guthrie, I.K. and Thompson, M. (2004) The Relations of Effortful Control and Impulsivity to Children's Resiliency and Adjustment. Child Development, 75, 25-46. http://dx.doi.org/10.1111/j.1467-8624.2004.00652.x

[66] Eisenberg, N. and Morris, A.S. (2002) Children’s Emotion-Related Regulation. In: Kail, R.V., Ed., Advances in Child Development and Behavior, Volume 30, Academic Press, San Diego, 189-229.

[67] Posner, M.I. (1980) Orienting of Attention. The Quarterly Journal of Experimental Psychology, 32, 3-25. http://dx.doi.org/10.1080/00335558008248231

[68] Fan, J. and Posner, M. (2004) Human Attentional Networks. Psychiatrische Praxis, 31, S210-S214. http://dx.doi.org/10.1055/s-2004-828484

[69] Rueda, M.R., Posner, M.I. and Rothbart, M.K. (2004) Attentional Control and Self-Regulation. In: Baumeister, R.F. and Vohs, K.D., Eds., Handbook of Self-Regulation: Research, Theory, and Applications, Guilford Press, New York, 283-300.

[70] Botvinick, M.M., Braver, T.S., Barch, D.M., Carter, C.S. and Cohen, J.D. (2001) Conflict Monitoring and Cognitive Control. Psychological Review, 108, 624-652. http://dx.doi.org/10.1037/0033-295X.108.3.624

[71] Posner, M.I. and Rothbart, M.K. (2004) Hebb’s Neural Networks Support the Integration of Psychological Science. Canadian Psychology/Psychologie Canadienne, 45, 265-278. http://dx.doi.org/10.1037/h0086997

[72] Posner, M.I. and Rothbart, M.K. (1992) Attentional Mechanisms and Conscious Experience. In: Milner, A.D. and Rugg, M.D., Eds., The Neuropsychology of Consciousness, Academic Press, San Diego, 91-111. http://dx.doi.org/10.1016/b978-0-12-498045-7.50010-4 
[73] Posner, M.I. and Rothbart, M.K. (1998) Summary and Commentary: Developing Attentional Skills. In: Edward, R.J., Ed., Cognitive Neuroscience of Attention: A Developmental Perspective, Lawrence Erlbaum Associates, Publishers, Mahwah, 317-323.

[74] Posner, M.I. and Rothbart, M.K. (2000) Developing Mechanisms of Self-Regulation. Development and Psychopathology, 12, 427-441. http://dx.doi.org/10.1017/S0954579400003096

[75] Davidson, R.J., Fox, A. and Kalin, N.H. (2007) Neural Bases of Emotion Regulation in Nonhuman Primates and Humans. In: Gross, J.J., Ed., Handbook of Emotion Regulation, Guilford Press, New York, 47-68.

[76] Rothbart, M.K. and Rueda, M.R. (2005) The Development of Effortful Control. In: Mayr, U., Awh, E., Keeleen, S.W. and Michael, I., Eds., Developing Individuality in the Human Brain: A Tribute to Michael I. Posner, American Psychological Association, Washington DC, 167-188. http://dx.doi.org/10.1037/11108-009

[77] Beauregard, M., Lévesque, J. and Bourgouin, P. (2001) Neural Correlates of Conscious Self-Regulation of Emotion. The Journal of Neuroscience, 21, 6993-7000.

[78] Ochsner, K.N., Bunge, S.A., Gross, J.J. and Gabrieli, J.D.E. (2002) Rethinking Feelings: An fMRI Study of the Cognitive Regulation of Emotion. Journal of Cognitive Neuroscience, 14, 1215-1229. http://dx.doi.org/10.1162/089892902760807212

[79] Dodge, K.A., Bates, J.E. and Pettit, G.S. (1990) Mechanisms in the Cycle of Violence. Science, 250, 1678-1683. http://dx.doi.org/10.1126/science.2270481

[80] Baumeister, R.F., Zell, A.L. and Tice, D.M. (2007) How Emotions Facilitate and Impair Self-Regulation. In: Gross, J.J., Ed., Handbook of Emotion Regulation, Guilford Press, New York, 408-426.

[81] Derryberr, D. and Rothbart, M.K. (2001) Early Temperament and Emotional Development. In: Kalverboer, A.F. and Gramsbergen, A., Eds., Handbook of Brain and Behavior in Human Development, Kluwer Academic, Dordrecht, 967988.

[82] Rothbart, M., Ziaie, H. and O’Boyle, C. (1992) Self-Regulation and Emotion in Infancy. In: Eisenberg, N. and Fabes, R., Eds., Emotion and Its Regulation in Early Development, Jossey-Bass/Pfeiffer, San Francisco, 7-23. http://dx.doi.org/10.1002/cd.23219925503

[83] Kochanska, G., Coy, K.C. and Murray, K.Y. (2001) The Development of Self-Regulation in the First Four Years of Life. Child Development, 72, 1091-1111. http://dx.doi.org/10.1111/1467-8624.00336

[84] Buss, K.A. and Goldsmith, H.H. (1998) Fear and Anger Regulation in Infancy: Effects on Temporal Dynamics of Affective Expression. Child Development, 69, 359-374. http://dx.doi.org/10.1111/j.1467-8624.1998.tb06195.x

[85] Diener, M., Mangelsdorf, S., McHale, J. and Frosch, C. (2002) Infants’ Behavioral Strategies for Emotion Regulation with Fathers and Mothers: Associations with Emotional Expressions and Attachment Quality. Infancy, 3, 153-174. http://dx.doi.org/10.1207/S15327078IN0302_3

[86] Stifter, C.A. and Braungart, J.M. (1995) The Regulation of Negative Reactivity in Infancy: Function and Development. Developmental Psychology, 31, 448-455. http://dx.doi.org/10.1037/0012-1649.31.3.448

[87] Kochanska, G. (2001) Emotional Development in Children with Different Attachment Histories: The First Three Years. Child Development, 72, 474-490. http://dx.doi.org/10.1111/1467-8624.00291

[88] Sroufe, L.A. (1996) Emotional Development: The Organization of Emotional Life in the Early Years. Cambridge University Press, New York. http://dx.doi.org/10.1017/CBO9780511527661

[89] Calkins, S.D. and Hill, A. (2007) Caregiver Influence on Emerging Emotion Regulation: Biological and Environmental Transactions in Early Development. In: Gross, J.J., Ed., Handbook of Emotion Regulation, Guilford Press, New York, 229-248.

[90] Stegge, H. and Terwog, M.M. (2007) Awareness and Regulation of Emotion in Typical and Atypical Development. In: Gross, J.J., Ed., Handbook of Emotion Regulation, Guilford Press, New York, 269-286.

[91] Caspi, A., Moffitt, T.E., Morgan, J., Rutter, M., Taylor, A., Arseneault, L., Tully, L., Jacobs, C., Kim-Cohen, J. and Polo-Tomas, M. (2004) Maternal Expressed Emotion Predicts Children’s Antisocial Behaviour Problems: Using Monozygotic-Twin Differences to Identify Environmental Effects on Behavioural Development. Developmental Psychology, 40, 149-161. http://dx.doi.org/10.1037/0012-1649.40.2.149

[92] Eisenberg, N., Zhou, Q. and Koller, S. (2001) Brazilian Adolescents’ Prosocial Moral Judgment and Behaviour: Relations to Sympathy, Perspective-Taking, Gender-Role Orientation, and Demographic Characteristics. Child Development, 72, 518-534. http://dx.doi.org/10.1111/1467-8624.00294

[93] Maughan, A. and Cicchetti, D. (2002) Impact of Child Maltreatment and Inter-Adult Violence on Children's Emotional Regulation Abilities and Socioemotional Adjustments. Child Development, 73, 1525-1542. http://dx.doi.org/10.1111/1467-8624.00488

[94] Valiente, C., Fabes, R.A., Eisenberg, N. and Spinrad, T.L. (2004) The Relations of Parental Expressivity and Support 
to Children’s Coping with Daily Stress. Journal of Family Psychology, 18, 97-106. http://dx.doi.org/10.1037/0893-3200.18.1.97

[95] Luna, B., Padmanabhan, A. and O’Hearn, K. (2010) What Has fMRI Told Us about the Development of Cognitive Control through Adolescence? Brain and Cognition, 72, 101-113. http://dx.doi.org/10.1016/j.bandc.2009.08.005

[96] Zeman, J., Cassano, M., Perry-Parrish, C. and Stegall, S. (2006) Emotion Regulation in Children and Adolescents. Journal of Developmental and Behavioral Pediatrics, 27, 155-168. http://dx.doi.org/10.1097/00004703-200604000-00014

[97] Elfenbein, H.A. and Ambady, N. (2002) On the Universality and Cultural Specificity of Emotion Recognition: A MetaAnalysis. Psychological Bulletin, 128, 203-235. http://dx.doi.org/10.1037/0033-2909.128.2.203

[98] Charles, S.T. and Carstensen, L.L. (2008) Unpleasant Situations Elicit Different Emotional Responses in Younger and Older Adults. Psychology and Aging, 23, 495-504. http://dx.doi.org/10.1037/a0013284

[99] Bandura, A., Caprara, G.V., Barbaranelli, C., Gerbino, M. and Pastorelli, C. (2003) Role of Affective Self-Regulatory Efficacy in Diverse Spheres of Psychosocial Functioning. Child Development, 74, 769-782. http://dx.doi.org/10.1111/1467-8624.00567

[100] Hubbard, J.A., Smithmyer, C.M., Ramsden, S.R., Parker, E.H., Flanagan, K.D., Dearing, K.F., Relyea, N. and Simons, R.F. (2002) Observational, Physiological, and Self-Report Measures of Children's Anger: Relations to Reactive versus Proactive Aggression. Child Development, 73, 1101-1118. http://dx.doi.org/10.1111/1467-8624.00460

[101] Crick, N.R. and Dodge, K.A. (1996) Social Information-Processing Mechanisms on Reactive and Proactive Aggression. Child Development, 67, 993-1002. http://dx.doi.org/10.2307/1131875

[102] Kazdin, A.E. (1995) Conduct Disorders in Childhood and Adolescence. 2nd Edition, Sage Publications, Inc., Thousand Oaks. http://dx.doi.org/10.4135/9781483345406

[103] Mullin, B.C. and Hinshaw, S.P. (2007) Emotion Regulation and Externalizing Disorders in Children and Adolescents. In: Gross, J.J., Ed., Handbook of Emotion Regulation, Guilford Press, New York, 523-541.

[104] Martel, M., Nikolas, M. and Nigg, J.T. (2007) Executive Function in Adolescents with ADHD. Journal of the American Academy of Child \& Adolescent Psychiatry, 46, 1437-1444. http://dx.doi.org/10.1097/chi.0b013e31814cf953

[105] Burt, K.B., Obradović, J., Long, J.D. and Masten, A.S. (2008) The Interplay of Social Competence and Psychopathology over 20 Years: Testing Transactional and Cascade Models. Child Development, 79, 359-374. http://dx.doi.org/10.1111/j.1467-8624.2007.01130.x

[106] Feingold, A. (1988) Cognitive Gender Differences Are Disappearing. American Psychologist, 43, 95-103. http://dx.doi.org/10.1037/0003-066X.43.2.95

[107] Halpern, D.F. (1997) Sex Differences in Intelligence: Implications for Education. American Psychologist, 52, 10911102. http://dx.doi.org/10.1037/0003-066X.52.10.1091

[108] Halpern, D.F. (2000) Sex Differences in Cognitive Abilities. 3rd Edition, Lawrence Erlbaum Associates Publishers, Mahwah.

[109] Kimura, M. (1992) Behavioral Modulation of Sensory Responses of Primate Putamen Neurons. Brain Research, 578, 204-214. http://dx.doi.org/10.1016/0006-8993(92)90249-9

[110] Weiss, E.M., Kemmler, G., Eberhard, A., Deisenhammer, E.A., Fleischhacker, W.W. and Delazer, M. (2003) Sex Differences in Cognitive Functions. Personality and Individual Differences, 35, 863-875. http://dx.doi.org/10.1016/S0191-8869(02)00288-X

[111] Overman, W.H., Bachevalier, J., Schuhmann, E. and Ryan, P. (1996) Cognitive Gender Differences in Very Young Children Parallel Biologically Based Cognitive Gender Differences in Monkeys. Behavioral Neuroscience, 110, 673684. http://dx.doi.org/10.1037/0735-7044.110.4.673

[112] Shaywitz, B.A., Shaywitz, S.E., Pugh, K.R., Constable, R.T., Skudlarski, P., Fulbright, R.K., et al. (1995) Sex Differences in the Functional Organization of the Brain for Language. Nature, 373, 607-609. http://dx.doi.org/10.1038/373607a0

[113] Krüger, R.J., Krüger, J.J., Hugo, R. and Campbell, N.G. (2001) Relationship Patterns between Central Auditory Processing Disorders and Language Disorders, Learning Disabilities, and Sensory Integration Dysfunction. Communication Disorders Quarterly, 22, 87-98. http://dx.doi.org/10.1177/152574010102200205

[114] Carlson, S. and Moses, L.J. (2001) Individual Differences in Inhibitory Control and Children’s Theory of Mind. Child Development, 72, 1032-1053. http://dx.doi.org/10.1111/1467-8624.00333

[115] Sternberg, R.J. (2004) Culture and Intelligence. American Psychologist, 59, 325-338. http://dx.doi.org/10.1037/0003-066X.59.5.325

[116] Smith, S.D., Kimberling, W.J. and Pennington, B.F. (1991) Screening for Multiple Genes Influencing Dyslexia. Read- 
ing and Writing: An Interdisciplinary Journal, 3, 285-298. http://dx.doi.org/10.1007/BF00354963

[117] Bettencourt, B.A. and Miller, N. (1996) Sex Differences in Aggression as a Function of Provocation: A Meta-Analysis. Psychological Bulletin, 119, 422-447. http://dx.doi.org/10.1037/0033-2909.119.3.422

[118] Eisenberg, N., Zhou, Q., Spinrad, T.L., Valiente, C., Fabes, R.A. and Liew, J. (2005) Relations among Positive Parenting, Children's Effortful Control, and Externalizing Problems: A Three-Wave Longitudinal Study. Child Development, 76, 1055-1071. http://dx.doi.org/10.1111/j.1467-8624.2005.00897.x

[119] Nigg, J.T. (2006) Temperament and Developmental Psychopathology. Journal of Child Psychology and Psychiatry, 47, 395-422. http://dx.doi.org/10.1111/j.1469-7610.2006.01612.x

[120] Gilliom, M., Shaw, D.S., Beck, J.E., Schonberg, M.A. and Lukon, J.L. (2002) Anger Regulation in Disadvantaged Preschool Boys: Strategies, Antecedents, and the Development of Self-Control. Developmental Psychology, 38, 222235. http://dx.doi.org/10.1037/0012-1649.38.2.222

[121] Lengua, L.J. (2006) Growth in Temperament and Parenting as Predictors of Adjustment during Children’s Transition to Adolescence. Developmental Psychology, 42, 819-832. http://dx.doi.org/10.1037/0012-1649.42.5.819

[122] Oldehinkel, A.J., Hartman, C.A., Ferdinand, R.F., Verhulst, F.C. and Ormel, J. (2007) Effortful Control as Modifier of the Association between Negative Emotionality and Adolescents' Mental Health Problems. Development and Psychopathology, 19, 523-539. http://dx.doi.org/10.1017/S0954579407070253

[123] Zeman, J., Shipman, K. and Suveg, C. (2002) Anger and Sadness Regulation: Predictions to Internalizing and Externalizing Symptoms in Children. Journal of Clinical Child and Adolescent Psychology, 31, 393-398. http://dx.doi.org/10.1207/S15374424JCCP3103_11

[124] Rubin, K.H., Bukowski, W.M. and Parker, J.G. (2006) Peer Interactions, Relationships, and Groups. In: Eisenberg, N., Damon, W. and Lerner, R.M., Eds., Handbook of Childpsychology: Volume 3, Social, Emotional, and Personality Development, 6th Edition, Wiley, New York, 571-645.

[125] Fishbein, D. (2000) The Importance of Neurobiological Research to the Prevention of Psychopathology. Prevention Science, 1, 89-106. http://dx.doi.org/10.1023/A:1010090114858

[126] Hawkins, K.A. and Trobst, K.K. (2000) Frontal Lobe Dysfunction and Aggression: Conceptual Issues and Research Findings. Aggression and Violent Behavior, 5, 147-157. http://dx.doi.org/10.1016/S1359-1789(98)00033-0

[127] Morgan, A. and Lilienfeld, S.O. (2000) A Meta-Analytic Review of the Relation between Antisocial Behavior and Neuropsychological Measures of Executive Function. Clinical Psychology Review, 20, 113-156. http://dx.doi.org/10.1016/S0272-7358(98)00096-8

[128] Paschall, M.J. and Fishbein, D.H. (2002) Executive Cognitive Functioning and Aggression: A Public Health Perspective. Aggression and Violent Behavior, 7, 215-235. http://dx.doi.org/10.1016/S1359-1789(00)00044-6

[129] Giancola, P.R. (2004) Executive Functioning and Alcohol-Related Aggression. Journal of Abnormal Psychology, 113, 541-555. http://dx.doi.org/10.1037/0021-843X.113.4.541

[130] Giancola, P.R. and Mezzich, A.C. (2000) Executive Cognitive Functioning Mediates the Relation between Language Competence and Antisocial Behavior in Conduct-Disordered Adolescent Females. Aggressive Behavior, 26, 359-375. http://dx.doi.org/10.1002/1098-2337(2000)26:5<359::AID-AB2>3.0.CO;2-B

[131] De Wall, C.N., Baumeister, R.F., Stillman, T.F. and Gailliot, M.T. (2007) Violence Restrained: Effects of Self-Regulation and Its Depletion on Aggression. Journal of Experimental Social Psychology, 43, 62-76. http://dx.doi.org/10.1016/j.jesp.2005.12.005

[132] Pahlavan, F., Mouchiroud, C. and Nemlaghi-Manis, E. (2012) Does Experience of Failure Decrease Executive, Regulatory Abilities and Increase Aggression? Global Journal of Health Science, 4, 60-87. http://dx.doi.org/10.5539/gjhs.v4n6p60

[133] Tangney, J.P., Baumeister, R.F. and Boone, A.L. (2004) High Self-Control Predicts Good Adjustment, Less Pathology, Better Grades, and Interpersonal Success. Journal of Personality, 72, 271-322. http://dx.doi.org/10.1111/j.0022-3506.2004.00263.x

[134] Sohlberg, M., McLaughlin, K.A., Pavese, A., Heidrich, A. and Posner, M. (2000) Evaluation of Attention Process Training and Brain Injury Education in Persons with Acquired Brain Injury. Journal of Clinical and Experimental Neuropsychology, 22, 656-676. http://dx.doi.org/10.1076/1380-3395(200010)22:5;1-9;FT656

[135] Kerns, K.A., Eso, K. and Thomson, J. (1999) Investigation of a Direct Intervention for Improving Attention in Young Children with ADHD. Developmental Neuropsychology, 16, 273-295. http://dx.doi.org/10.1207/S15326942DN1602_9

[136] Klingberg, T., Forssberg, H. and Westerberg, H. (2002) Training of Working Memory in Children with ADHD. Journal of Clinical and Experimental Neuropsychology, 24, 781-791. http://dx.doi.org/10.1076/jcen.24.6.781.8395

[137] Rumbaugh, D.M. and Washburn, D.A. (2003) Intelligence of Apes and Other Rational Beings. Yale University Press, New Haven. http://dx.doi.org/10.12987/yale/9780300099836.001.0001 
[138] Moses, L.J. and Carlson, S.M. (2004) Self-Regulation and Children’s Theories of Mind. In: Lightfoot, C., Lalonde, C. and Michael, M.C., Eds., Changing Conceptions of Psychological Life, Lawrence Erlbaum Associates Publishers, Mahwah, 127-146.

[139] Milner, B. (1963) Effect of Different Brain Lesions on Card Sorting. Archives of Neurology, 9, 90-100. http://dx.doi.org/10.1001/archneur.1963.00460070100010

[140] Berg, E.A. (1948) A Simple Objective Technique for Measuring Flexibility in Thinking. Journal of General Psychology, 39, 15-22. http://dx.doi.org/10.1080/00221309.1948.9918159

[141] Monchi, O., Petrides, M., Petre, V., Worsley, K. and Dagher, A. (2001) Wisconsin Card Sorting Revisited: Distinct Neural Circuits Participating in Different Stages of the Task Identified by Event-Related Functional Magnetic Resonance Imaging. The Journal of Neuroscience, 21, 7733-7741.

[142] O’Connor, D.B., Archer, J. and Wu, F.W.C. (2001) Measuring Aggression: Self-Reports, Partner Reports, and Responses to Provoking Scenarios. Aggressive Behavior, 27, 79-101. http://dx.doi.org/10.1002/ab.2

[143] Pahlavan, F., Amirrezvani, A. and O’Connor, D.B. (2012) Validation and Application of the French Version of the Aggressive Provocation Questionnaire: Gender and Age Differences in Aggression. Psychology, 3, 1035-1048. http://dx.doi.org/10.4236/psych.2012.312155

[144] Pahlavan, F., Drozda-Senkowska, E. and Michelot, J. (2007) Pratiques des jeux vidéos violents et agression. Les Cahiers Internationaux de Psychologie Sociale, 75-76, 31-63. http://dx.doi.org/10.3917/cips.075.0051

[145] Spielberger, C.D. (1993) Inventaire d’Anxiété Etat-Trait forme Y. Centre de Psychologie Appliquée, Paris.

[146] Kochanska, G., Murray, K. and Coy, K.C. (1997) Inhibitory Control as a Contributor to Conscience in Childhood: From Toddler to Early School Age. Child Development, 68, 263-277. http://dx.doi.org/10.2307/1131849

[147] Cortina, J.M. (1993) What Is Coefficient Alpha: An Examination of Theory and Applications? Journal of Applied Psychology, 78, 98-104. http://dx.doi.org/10.1037/0021-9010.78.1.98

[148] Rabbitt, P. (1997) Methodologies and Models in the Study of Executive Function. In: Rabbitt, P., Ed., Methodology of Frontal and Executive Function, Psychology Press Ltd., Hove, 1-38.

[149] Wyer, R.S., Ed. (2004) Social Comprehension and Judgment: The Role of Situation Models, Narratives, and Implicit Theories. Lawrence Erlbaum Associates, Mahwah. 